\title{
Living Olefin Polymerization and Block Copolymer Formation with FI Catalysts
}

\author{
Atsushi SAKUMA, Marc-Stephan WeISER, and Terunori FuJitA ${ }^{\dagger}$ \\ Mitsui Chemicals, Inc., R\&D Center, 580-32 Nagaura, Sodegaura-City 299-0265, Japan
}

(Received November 6, 2006; Accepted December 14, 2006; Published January 24, 2007)

\begin{abstract}
This contribution reports on the recent advances in living olefin polymerization catalysis and block copolymer formation made by fluorinated bis(phenoxy-imine)Ti complexes (fluorinated Ti-FI catalysts), which were discovered by Mitsui Chemicals. Fluorinated Ti-FI catalysts are capable of mediating thermally robust living ethylene and highly stereoselective living propylene polymerization. This highly controlled living nature has made it possible to synthesize a wide variety of monodisperse polymers, functionalized polymers and block copolymers from ethylene, propylene, higher $\alpha$-olefins, cyclic olefins and styrene. The living FI polymers possess unique and often previously inaccessible microstructures, and some of the FI polymers were revealed to display unique morphologies and useful material properties. Therefore, the discovery and development of the fluorinated Ti-FI catalysts has not only made a significant impact on living olefin polymerization catalysis but has also given industry opportunities to make unique polyolefin-based materials for the benefit of the world at large. [doi:10.1295/polymj.PJ2006152]

KEY WORDS FI Catalyst / Living Polymerization / Block Copolymer / Fluorinated / Syndiotactic / Monodisperse /
\end{abstract}

Producing polymers with perfectly controlled molecular weight, molecular weight distribution, composition and architecture has been an ultimate goal in the field of polymer synthesis. Living olefin polymerization permits consecutive enchainment of monomer units without termination, and thus is an excellent way of synthesizing polyolefin-based block copolymers and chain-end functionalized polyolefins as well as precisely controlling molecular weight and composition. ${ }^{1}$ These living polymers have the potential to be excellent compatibilizers, modifiers, additives and elastomers.

Since Doi's pioneering work on living propylene polymerization using a vanadium-based catalyst, ${ }^{2}$ much effort has been devoted to the discovery and development of catalysts capable of mediating the living polymerization of olefinic monomers. Recent progress in the rational design of transition metal complexes for olefin polymerization ${ }^{3}$ has spurred the development of high performance catalysts based on both early and late transition metal complexes for living olefin polymerization. ${ }^{4}$ Recent reviews cover much of this work. $^{5}$

Researchers at Mitsui Chemicals developed phenoxy-imine ligated early transition metal complexes for the controlled (co)polymerization of olefinic monomers (now known as FI catalysts), ${ }^{6,7}$ capable of producing a wide variety of unique polymers including selective vinyl- and Al-terminated polyethylenes (PEs), well-defined multimodal PEs, highly isotactic and syndiotactic polypropylenes (iPPs and sPPs), and regio- and stereoirregular high molecular weight poly(higher $\alpha$-olefin)s. ${ }^{8}$ After extensive research on FI catalysts, Mitsui researchers in 1999 discovered fluorinated Ti-FI catalysts that can promote unprecedented living ethylene and propylene polymerizations, resulting in the formation of functionalized polymers and block copolymers from ethylene, propylene and higher $\alpha$-olefins. ${ }^{7,9-11}$

The above results have stimulated even further research on FI catalysts and related complexes. In particular, studies performed after 2001 by Coates, Pellecchia, Mülhaupt and associated coworkers have contributed significantly to the synthesis of living polymers using fluorinated Ti-FI catalysts, which include PE- $b$-poly(ethylene-co-cyclopentene) and PE$b$-polystyrene (PE- $b$-PS). ${ }^{7,10,12,13}$

This review provides a comprehensive survey of living olefin polymerization and block copolymer formation with fluorinated Ti-FI catalysts, covering the literature, including the important patent literature, until the middle of 2006. The morphologies and material properties of some of the living FI polymers are also introduced. 


\section{DISCOVERY OF FLUORINATED \\ TI-FI CATALYSTS FOR LIVING OLEFIN POLYMERIZATION}

\section{LIVING ETHYLENE POLYMERIZATION}

The FI catalysts and related complexes that are introduced in this paper are collected in Table I.

Table I. Structures of FI Catalysts and related complexes

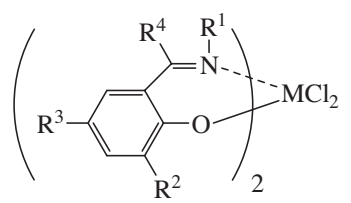

\begin{tabular}{|c|c|c|c|c|c|}
\hline Catalyst & $\mathrm{M}$ & $\mathrm{R}^{1}$ & $\mathrm{R}^{2}$ & $\mathrm{R}^{3}$ & $\mathrm{R}^{4}$ \\
\hline 1 & $\mathrm{Ti}$ & $\mathrm{Ph}$ & ${ }^{t} \mathrm{Bu}$ & $\mathrm{H}$ & $\mathrm{H}$ \\
\hline 2 & $\mathrm{Ti}$ & $\mathrm{Ph}$ & ${ }^{t} \mathrm{Bu}$ & $\mathrm{H}$ & Et \\
\hline 3 & $\mathrm{Ti}$ & $\mathrm{Ph}$ & ${ }^{t} \mathrm{Bu}$ & $\mathrm{Me}$ & $\mathrm{Et}$ \\
\hline 4 & $\mathrm{Ti}$ & $\mathrm{Ph}$ & ${ }^{t} \mathrm{Bu}$ & ${ }^{t} \mathrm{Bu}$ & $\mathrm{Ph}$ \\
\hline 5 & \multicolumn{5}{|c|}{ See the structure below } \\
\hline 6 & $\mathrm{Zr}$ & Pentafuluorophenyl & ${ }^{t} \mathrm{Bu}$ & $\mathrm{H}$ & $\mathrm{H}$ \\
\hline 7 & $\mathrm{Hf}$ & Pentafuluorophenyl & ${ }^{t} \mathrm{Bu}$ & $\mathrm{H}$ & $\mathrm{H}$ \\
\hline 8 & $\mathrm{Zr}$ & $\mathrm{Ph}$ & ${ }^{t} \mathrm{Bu}$ & $\mathrm{H}$ & $\mathrm{H}$ \\
\hline 9 & $\mathrm{Hf}$ & $\mathrm{Ph}$ & ${ }^{t} \mathrm{Bu}$ & $\mathrm{H}$ & $\mathrm{H}$ \\
\hline 10 & $\mathrm{Ti}$ & Pentafuluorophenyl & ${ }^{t} \mathrm{Bu}$ & $\mathrm{H}$ & $\mathrm{H}$ \\
\hline 11 & $\mathrm{Ti}$ & 2,6-Difuluorophenyl & I & $\mathrm{I}$ & $\mathrm{H}$ \\
\hline 12 & $\mathrm{Ti}$ & Pentafuluorophenyl & Cyclohexyl & $\mathrm{H}$ & $\mathrm{H}$ \\
\hline 13 & $\mathrm{Ti}$ & Pentafuluorophenyl & ${ }^{i} \operatorname{Pr}$ & $\mathrm{H}$ & $\mathrm{H}$ \\
\hline 14 & $\mathrm{Ti}$ & Pentafuluorophenyl & $\mathrm{Me}$ & $\mathrm{H}$ & $\mathrm{H}$ \\
\hline 15 & $\mathrm{Ti}$ & Pentafuluorophenyl & $\mathrm{H}$ & $\mathrm{H}$ & $\mathrm{H}$ \\
\hline 16 & $\mathrm{Ti}$ & 2-Fuluorophenyl & ${ }^{t} \mathrm{Bu}$ & $\mathrm{H}$ & $\mathrm{H}$ \\
\hline 17 & $\mathrm{Ti}$ & 2-Me-phenyl & ${ }^{t} \mathrm{Bu}$ & $\mathrm{H}$ & $\mathrm{H}$ \\
\hline 18 & $\mathrm{Ti}$ & $2-{ }^{i}$ Pr-Phenyl & ${ }^{t} \mathrm{Bu}$ & $\mathrm{H}$ & $\mathrm{H}$ \\
\hline 19 & $\mathrm{Ti}$ & $\mathrm{Ph}$ & $\mathrm{SiMe}_{3}$ & $\mathrm{H}$ & $\mathrm{H}$ \\
\hline 20 & $\mathrm{Ti}$ & $\mathrm{Ph}$ & $\mathrm{Me}$ & $\mathrm{H}$ & $\mathrm{H}$ \\
\hline 21 & $\mathrm{Ti}$ & 3,5-Difuluorophenyl & $\mathrm{Me}$ & $\mathrm{Me}$ & $\mathrm{H}$ \\
\hline 22 & $\mathrm{Ti}$ & Pentafuluorophenyl & ${ }^{t} \mathrm{Bu}$ & ${ }^{t} \mathrm{Bu}$ & $\mathrm{H}$ \\
\hline 23 & $\mathrm{Ti}$ & Pentafuluorophenyl & $\mathrm{SiMe}_{3}$ & $\mathrm{H}$ & $\mathrm{H}$ \\
\hline 24 & $\mathrm{Hf}$ & Cyclohexyl & Adamantyl & $\mathrm{Me}$ & $\mathrm{H}$ \\
\hline 25 & $\mathrm{Ti}$ & Pentafuluorophenyl & $\mathrm{Me}$ & $\mathrm{Me}$ & $\mathrm{Ph}$ \\
\hline 26 & $\mathrm{Ti}$ & Pentafuluorophenyl & $\mathrm{Br}$ & $\mathrm{Br}$ & $\mathrm{H}$ \\
\hline 27 & $\mathrm{Ti}$ & Pentafuluorophenyl & $\mathrm{CF}_{3}$ & $\mathrm{H}$ & $\mathrm{H}$ \\
\hline 28 & \multicolumn{5}{|c|}{ See the structure below } \\
\hline 29 & $\mathrm{Ti}$ & 2,4,6-Trifuluorophenyl & ${ }^{t} \mathrm{Bu}$ & $\mathrm{H}$ & $\mathrm{H}$ \\
\hline 30 & $\mathrm{Ti}$ & 2,4,6-Trifuluorophenyl & Cumyl & $\mathrm{Me}$ & $\mathrm{H}$ \\
\hline 31 & $\mathrm{Zr}$ & 2,6-Difuluorophenyl & I & I & $\mathrm{H}$ \\
\hline
\end{tabular}
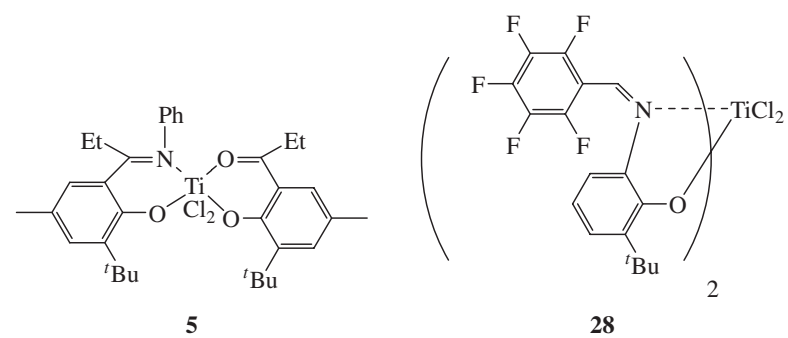

Researchers at Mitsui Chemicals have shown that, in general, among group 4 metal FI catalysts in combination with methylaluminoxane (MAO), a Ti-FI catalyst produces the highest molecular weight PE, and in addition, it often possesses a molecular weight distribution $\left(M_{\mathrm{w}} / M_{\mathrm{n}}\right)$ smaller than 2 , suggesting that a Ti-FI catalyst can afford a higher ratio rate of chain propagation to chain transfer relative to the $\mathrm{Zr}$ - and Hf-congeners (e.g., $1,25^{\circ} \mathrm{C}$ polymerization, $5 \mathrm{~min}$; $\left.M_{\mathrm{w}} 274000, M_{\mathrm{w}} / M_{\mathrm{n}} 1.61\right)^{6,7,8 \mathrm{a}}$ Indeed, Furuyama and Fujita have demonstrated that Ti-FI catalysts have some living ethylene polymerization characteristics and can produce very narrow molecular weight distribution PEs under specifically controlled conditions (e.g., short polymerization time and/or controlled ethylene concentration in a polymerization medium). For example, they have described that nearly monodisperse PEs can be formed by $1 /$ MAO ( 1 min polymerization, atmospheric pressure, $25^{\circ} \mathrm{C} ; M_{\mathrm{n}} 52000$, $\left.M_{\mathrm{w}} / M_{\mathrm{n}} 1.12,50^{\circ} \mathrm{C} ; M_{\mathrm{n}} 65000, M_{\mathrm{w}} / M_{\mathrm{n}} 1.17\right)$ and $2 /$ MAO (1 min polymerization, atmospheric pressure, $\left.25^{\circ} \mathrm{C} ; M_{\mathrm{n}} 8000, M_{\mathrm{w}} / M_{\mathrm{n}} 1.05\right) .{ }^{8 \mathrm{~g}, 10 \mathrm{~b}}$ In addition, TiFI catalysts 3 and $\mathbf{4}$ with MAO were also reported by Reinartz, Coates, Suzuki and Fujita to produce nearly monodisperse PEs under limited conditions. ${ }^{14,15}$ With these Ti-FI catalysts, however, synthesizing high molecular weight and narrow molecular weight distribution PEs is normally difficult (e.g., $5 \mathrm{~min}$ polymerization, atmospheric pressure, $50^{\circ} \mathrm{C}$; $1, M_{\mathrm{n}} 132000, M_{\mathrm{w}} / M_{\mathrm{n}} 1.83,2, M_{\mathrm{n}} 24000, M_{\mathrm{w}} / M_{\mathrm{n}}$ 1.46). ${ }^{10 \mathrm{~b}}$ Moreover, generally, these catalysts cannot be applied to block copolymer formation. Regarding this quasi-living nature, Suzuki and Fujita have demonstrated that a phenoxy-imine and phenoxy-ketone ligated $\mathrm{Ti}$ complex 5 (heteroligated phenoxy-based Ti complex) does not induce quasi-living ethylene polymerization under the conditions where the corresponding Ti-FI catalyst 3 mediates the polymerization in a quasi-living fashion. ${ }^{15}$

A pivotal discovery concerning the development of living FI catalysts, made by Mitani, Saito, Ishii and Fujita, is the remarkable effect of a perfluorophenyl $\left(\mathrm{C}_{6} \mathrm{~F}_{5}\right)$ substituent on chain transfer behavior. ${ }^{9-11,16}$ Namely, they found that the introduction of the $\mathrm{C}_{6} \mathrm{~F}_{5}$ group on the imine- $\mathrm{N}$ in place of the $\mathrm{C}_{6} \mathrm{H}_{5}$ group for Zr- and Hf-FI catalysts 6 and 7 resulted in the formation of enormously enhanced (more than 20 times greater) molecular weight PEs (5 min polymerization, $25^{\circ} \mathrm{C}, M_{\mathrm{w}} ; 8$ 7000, 6 157000; 9 17000, 7 410000), even though the increase in catalytic activity is merely 40-50\%. ${ }^{16,17}$ Additionally, and more importantly, they discovered that Ti-FI catalyst 10 combined with MAO mediates living ethylene polymerization at a high temperature of $50{ }^{\circ} \mathrm{C}$ and yields a very high molecular weight $\mathrm{PE}$ with an extremely 
Table II. Ethylene polymerization results with FI catalysts 10 and $\mathbf{1 2}-\mathbf{1 5} / \mathrm{MAO}^{\mathrm{a}}$

\begin{tabular}{ccccc}
\hline FI catalyst & $\begin{array}{c}\text { yield } \\
(\mathrm{g})\end{array}$ & $\begin{array}{c}M_{\mathrm{n}}{ }^{\mathrm{b}} \\
\left(\times 10^{-3}\right)\end{array}$ & $M_{\mathrm{w}} / M_{\mathrm{n}}{ }^{\mathrm{b}}$ & $\begin{array}{c}T_{\mathrm{m}}{ }^{\mathrm{c}} \\
\left({ }^{\circ} \mathrm{C}\right)\end{array}$ \\
\hline $\mathbf{1 0}$ & 0.28 & 412 & 1.13 & 136 \\
$\mathbf{1 2}$ & 0.29 & 49 & 1.05 & 134 \\
$\mathbf{1 3}$ & 0.32 & 51 & 1.10 & 135 \\
$\mathbf{1 4}$ & 0.47 & 75 & 1.16 & 136 \\
$\mathbf{1 5}$ & 0.21 & 44 & 1.08 & 134 \\
\hline
\end{tabular}

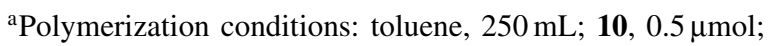
12-15, $5 \mu \mathrm{mol}$; MAO, $1.25 \mathrm{mmol}$; ethylene, $100 \mathrm{~L} / \mathrm{h}$; time, $1 \mathrm{~min}$; temperature, $25^{\circ} \mathrm{C}$. ${ }^{\mathrm{b}}$ Determined by GPC using polyethylene calibration. ${ }^{\mathrm{c}}$ Determined by DSC.

narrow molecular weight distribution $\left(M_{\mathrm{n}} 424000\right.$, $\left.M_{\mathrm{w}} / M_{\mathrm{n}} 1.13\right) .{ }^{9}{ }^{90,11 \mathrm{a}, 18}{ }^{13} \mathrm{C}$ NMR and IR analysis have suggested that the PE possesses a linear structure with virtually no branching (branching less than 1 per 1000 carbon atoms, melting temperature $\left.\left(T_{\mathrm{m}}\right) 135^{\circ} \mathrm{C}\right)$. The living nature was confirmed by the linear relationship between $M_{\mathrm{n}}$ and polymerization time as well as by the narrow molecular weight distributions observed. Surprisingly, at higher temperatures such as $75^{\circ} \mathrm{C}$ and even at $90^{\circ} \mathrm{C}$, this catalyst furnishes very narrow molecular weight distribution PEs $\left(M_{\mathrm{w}} / M_{\mathrm{n}}<1.3\right) .{ }^{18}$ These results provided by Mitani, Saito, Ishii and Fujita indicate that Ti-FI catalyst $\mathbf{1 0}$ initiates highly controlled, thermally robust living ethylene polymerization. Interestingly, using Ti-FI catalyst $\mathbf{1 1}$ bearing iodines in the ligand, Weiser and Mülhaupt prepared ultra-high molecular weight PE with a fairly narrow molecular weight distribution $\left(M_{\mathrm{w}} 5500000, M_{\mathrm{w}} / M_{\mathrm{n}}\right.$ 1.57). ${ }^{19}$

Furuyama and Fujita have shown that a series of TiFI catalysts $\mathbf{1 0}$ and 12-15 having a $t$-Bu, cyclohexyl, $i$-Pr, Me and $\mathrm{H}$ ortho to the phenoxy-O (thus having various steric environments in close proximity to the polymerization site) all promote room temperature living ethylene polymerization, though, for the nonfluorinated congeners, the steric bulk of the substituent ortho to the phenoxy-O significantly influences product molecular weight [Table II] ${ }^{8 g, 20}$

These facts indicate that, for fluorinated Ti-FI catalysts, the steric hindrance provided by the substutuent ortho to the phenoxy-O exercises no significant influence on the living nature, implying that steric factors do not play an important role in the achievement of the living polymerization. ${ }^{10}$

Although the first discovery was made with the $\mathrm{C}_{6} \mathrm{~F}_{5}$ substituent, Mitani and Fujita have revealed that only a single ortho- $\mathrm{F}$ is a requirement for achieving living ethylene polymerization. ${ }^{18,21}{ }^{13} \mathrm{C} \mathrm{NMR}$ and IR analysis have shown that the PEs arising from nonfluorinated Ti-FI catalysts possess a high degree of vinyl unsaturation at one of the two polymer chain-ends, indicating that $\beta-\mathrm{H}$ transfer is the dominant termination reaction. Accordingly, the ortho-F suppresses the $\beta$-H transfer.

One should note that, though the ortho-fluorinated Ti-FI catalyst $\mathbf{1 6}$ induces the living polymerization, the corresponding non-fluorinated and ortho-methylated Ti-FI catalysts $\mathbf{1}$ and $\mathbf{1 7}$ do not initiate the living polymerization under the same conditions. ${ }^{8 g}$ The experimental evidence described above indicates that steric hindrance provided by the ortho-F does not play a key role in the achievement of living ethylene polymerization, suggesting that the ortho-F is involved electronically in the achievement of highly controlled living polymerization. ${ }^{10}$

Furuyama and Fujita have reported that Ti-FI catalyst 18, having a 2-isopropylphenyl group on the imine-N, generates PE with a $M_{\mathrm{w}} / M_{\mathrm{n}}$ of $1.29\left(M_{\mathrm{w}}\right.$ 29600), ${ }^{8 \mathrm{~g}}$ suggesting that the introduction of considerable steric congestion near the polymerization center can achieve a high ratio for the rates of propagationto-chain transfer (which is well-known behavior; bulkier ligands decrease chain transfer), but at the cost of significantly reduced catalytic activity in the case of a Ti-FI catalyst. ${ }^{3 e}$

\section{LIVING PROPYLENE POLYMERIZATION}

Fujita and Mitani have demonstrated that, despite being $C_{2}$-symmetric catalysts, Ti-FI catalysts with MAO activation can mediate highly syndiospecific propylene polymerization. ${ }^{6,7,9}$ For example, Ti-FI catalyst 19 produces highly syndiotactic $\mathrm{PP}\left(1^{\circ} \mathrm{C}\right.$ polymerization: $\left.r r r r 84 \%, T_{\mathrm{m}} 140^{\circ} \mathrm{C}\right) .{ }^{8 \mathrm{~g}}{ }^{13} \mathrm{C}$ NMR spectrum for the sPP is shown in Figure 1.

The propylene polymerization was revealed to proceed via a chain-end control mechanism featuring unusual 2,1-insertion. ${ }^{11 \mathrm{c}, 12 \mathrm{c}, \mathrm{d}}$ The stereoselectivity and $T_{\mathrm{m}}$ introduced above are exceptionally high for a chain-end control mechanism.

Mitani, Furuyama and Fujita have revealed that, surprisingly, through the chain-end control mechanism, the steric bulk of the substituent that is ortho to the phenoxy-oxygen plays a decisive role in determining the syndioselectivity of the polymerization, and the sterically hindered ortho-substituent results in the formation of highly syndiotactic PPs (i.e., sterically less hindered ortho-substituents lead to the production of lower tacticity PPs). ${ }^{7 \mathrm{c}, \mathrm{d}, \mathrm{g}, 8 \mathrm{~g}, 22}$ They have given the name "ligand-directed chain-end-controlled polymerization" to this type of chain-end controlled polymerization, which is evidently governed by the ligand structure and can be highly stereoselective.

On the basis of QM/MM calculations, Milano and Cavallo have suggested that, for propylene polymerization with fluorinated Ti-FI catalysts, stereocontrol 


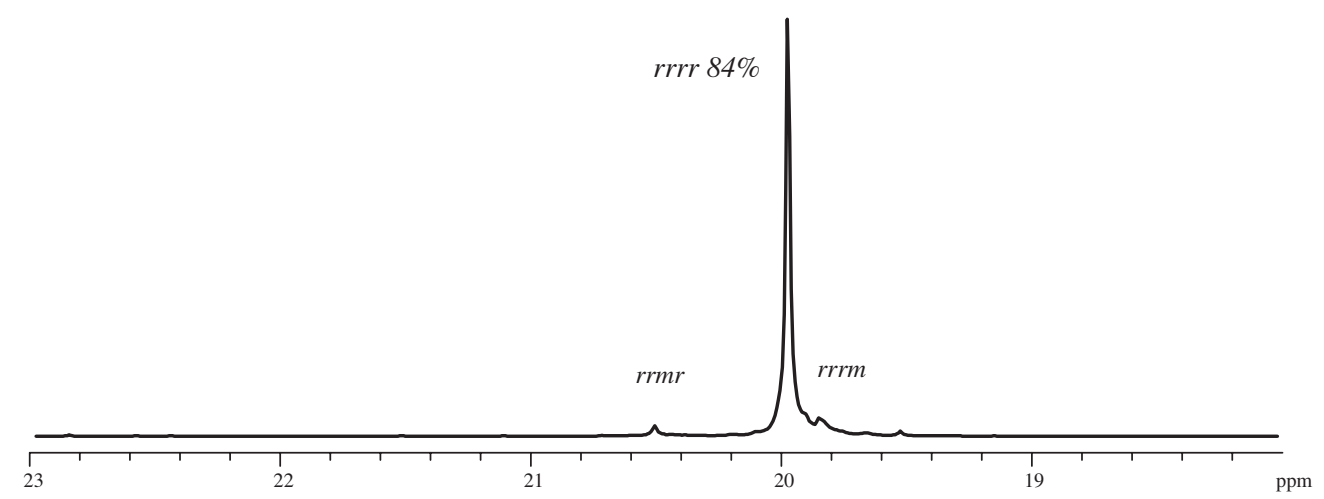

Figure 1. ${ }^{13} \mathrm{C}$ NMR spectrum for the sPP formed with FI catalyst 19/MAO.

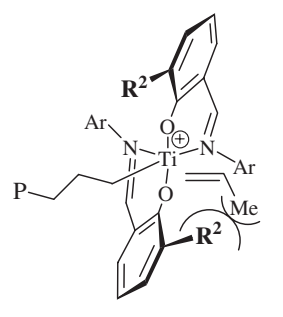

Disfavored

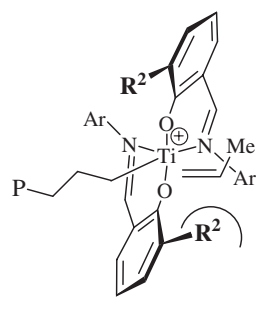

Favored

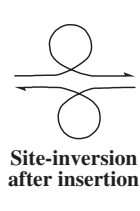

$\underline{\Lambda \text { form }}$

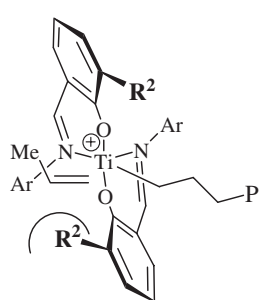

Favored

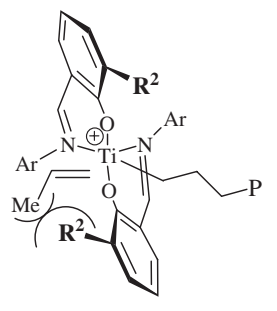

Disfavored $\underline{\Delta \text { form }}$

Figure 2. Proposed mechanism of site-inversion for syndioselective propylene polymerization with Ti-FI catalysts.

cannot be achieved by the direct interaction between the methyl group of propylene and the $\beta$-C of a growing polymer chain (distance $>4 \AA$ ), and instead, the chirality of the octahedral site $(\Lambda$ and $\Delta)$ dictates the chirality of the coordination of propylene. ${ }^{23}$ This mechanism of stereocontrol requires that Ti-FI catalysts should be fluxional between $\Lambda$ and $\Delta$ forms, the inter-conversion rate of which is faster than chain propagation. Ti-FI catalysts are likely to be fluxional in solution, as was already reported for some $\mathrm{Zr}$-FI catalysts by Tohi and Fujita and relevant complexes by Bei and Jordan. ${ }^{24}$

Based on the calculation results together with the experimental data described above, Mitani and Fujita have concluded that a site inversion between propylene insertions (i.e., fluxional isomerization between the $\Lambda$ and $\Delta$ forms at a rate which is faster than chain propagation) that provides enantiomeric sites is responsible for this chain-end controlled polymerization capable of producing highly syndioselective PPs [Figure 2]. ${ }^{7 \mathrm{c}, \mathrm{d}, \mathrm{g}, 10 \mathrm{~b}, 22}$ The site-inversion mechanism leads to the concept that if propylene insertion is faster than site-inversion, a $C_{2}$-symmetric Ti-FI catalyst with sufficient steric bulk ortho to the phenoxy-O can be a catalyst for the isospecific polymerization of propylene, considering the catalyst structure and catalyst performance relationships established by researchers at Mitsui Chemicals. . $^{\mathrm{cc}, \mathrm{d}, \mathrm{g}, 10 \mathrm{~b}, 22}$
Ti-FI catalysts with no ortho-Fs in the ligands can also display some living propylene polymerization characteristics. Furuyama and Fujita have revealed that Ti-FI catalyst $\mathbf{2 0}$ having a Me group ortho to the phenoxy-O can form high molecular weight PP $\left(M_{\mathrm{w}} 101000\right)$ with a fairly narrow molecular weight distribution of 1.47 at $1{ }^{\circ} \mathrm{C}$, though the PP produced has an atactic nature. ${ }^{8 \mathrm{~g}}$ Recently, Cherian and Coates reported on Ti-FI catalyst $\mathbf{2 1}$ bearing the Me group ortho to the phenoxy-O and a 3,5-difluorophenyl group on the imine-N, ${ }^{21}$ which forms nearly monodisperse atactic PPs $\left(M_{\mathrm{n}} 240000, M_{\mathrm{w}} / M_{\mathrm{n}} 1.13\right)$ at $0^{\circ} \mathrm{C}^{13 \mathrm{f}}$ These facts suggest that the introduction of a sterically less encumbered group ortho to the phenoxy-O together with the incorporation of meta-Fs to the aryl group on the imine- $\mathrm{N}$ is effective for the achievement of a high ratio rate of chain propagation to chain transfer at the expense of the loss of stereoselectivity.

Mitani and Fujita discovered in 1999 that the introduction of the $\mathrm{C}_{6} \mathrm{~F}_{5}$ group on the imine- $\mathrm{N}$ also induces an unprecedented living polymerization effect with propylene. ${ }^{9-11}$ On activation with MAO, Ti-FI catalyst 10 enables room temperature living propylene polymerization and afforded highly syndiotactic PP $\left(M_{\mathrm{n}}\right.$ $\left.28500, M_{\mathrm{w}} / M_{\mathrm{n}} 1.11, r r 87 \%, T_{\mathrm{m}} 137^{\circ} \mathrm{C}\right)$, representing the first living catalyst capable of high levels of stereocontrol in propylene polymerization. Addition- 
ally, this FI catalyst is the first example of a catalyst that mediates the living polymerization of both ethylene and propylene. ${ }^{9-11}$ Mason and Coates reported that, as for the living ethylene polymerization, only a single ortho-F is required in order to achieve living propylene polymerization, again demonstrating the remarkable ortho-F effect. ${ }^{25}$ This fact implies that steric factors do not play a key role in the realization of the living polymerization of propylene with fluorinated Ti-FI catalysts.

A combinatorial method has contributed significantly to the further development of Ti-FI catalysts for propylene polymerization. Based on a self-developed combinatorial method that includes the separation of insoluble sPPs from soluble atactic PPs, ${ }^{26}$ Tian and Coates have acquired Ti-FI catalyst $\mathbf{2 2}$ that is a modified version of 10. ${ }^{9-11}$ In 2001, they reported that, upon activation with MAO, 22 produces highly syndiotactic monodisperse $\mathrm{PP}\left(0^{\circ} \mathrm{C}\right.$ polymerization; $\mathrm{rrr}$ $96 \%, T_{\mathrm{m}} 148^{\circ} \mathrm{C}$ ) though the reported stereoselectivity and $T_{\mathrm{m}}$ are very high compared to the data obtained by Mitani and Fujita under analogous conditions. ${ }^{12 a, 22}$ Additionally, using gel permeation chromatography (GPC) as a combinatorial screening method, Mason and Coates have revealed that living ligand (orthofluorinated ligand) and non-living ligand (ortho-nonfluorinated ligand) combinations resulted in highly active catalysts. ${ }^{27}$ These results show the usefulness of a combinatorial approach for the rapid screening of catalysts for propylene polymerization, which can drastically reduce the number of reactions needed to identify useful catalysts.

Furuyama, Mitani and Fujita have revealed the structure and catalytic performance relationships including the remarkable effect of the substituent ortho to the phenoxy-O on stereoselectivity and catalytic activity, ${ }^{7 \mathrm{c}, \mathrm{d}, \mathrm{g}, 8 \mathrm{~g}, 10 \mathrm{~b}, 22}$ some of which has recently been confirmed by Cherian and Coates. ${ }^{13 \mathrm{f}}$ Based on these relationships, Mitani, Fujita, Weiser and Mülhaupt successfully obtained atactic to highly syndiotactic monodisperse PPs with high efficiency. ${ }^{19,22}$ For example, Mitani and Fujita have demonstrated that Ti-FI catalyst 23/MAO yields highly syndiotactic monodisperse PP $\left(25^{\circ} \mathrm{C}\right.$ polymerization: $r r$ 93\%, $M_{\mathrm{n}}$ $\left.47000, M_{\mathrm{w}} / M_{\mathrm{n}} 1.08\right)$ with an exceptionally high $T_{\mathrm{m}}$ of $152^{\circ} \mathrm{C}$. Surprisingly, at a temperature of $50^{\circ} \mathrm{C}$, 23 produces highly syndiotactic PP with an extremely narrow $M_{\mathrm{w}} / M_{\mathrm{n}}$ of 1.18 and with a very high $T_{\mathrm{m}}$ of $150^{\circ} \mathrm{C}$, which is highly unusual for a chain-end controlled polymerization because chain-end control operates well at very low to sub-ambient temperatures and loses its stereoregulating ability at elevated temperatures. $^{22}$

Interestingly, Nakayama and Fujita have demonstrated that 23 combined with $\mathrm{MgCl}_{2} / i-\mathrm{Bu}_{\mathrm{n}} \mathrm{Al}(\mathrm{OR})_{3-\mathrm{n}}$

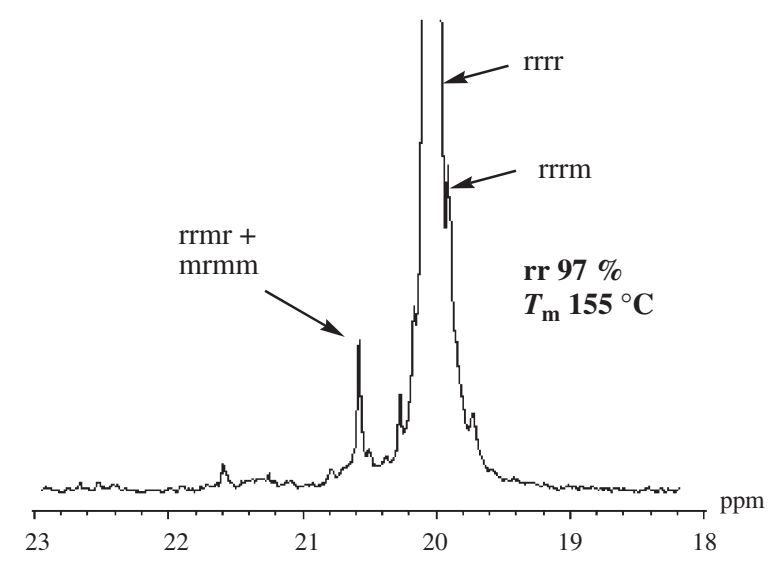

Figure 3. ${ }^{13} \mathrm{C}$ NMR spectrum for the $\mathrm{sPP}$ formed with $\mathrm{MgCl}_{2}$-supported Ti-FI catalyst 23.

(MAO-free, $\mathrm{MgCl}_{2}$-supported catalyst system) produces higher tacticity PP with higher $T_{\mathrm{m}}(r r$ 97\%, $T_{\mathrm{m}} 155^{\circ} \mathrm{C}$ ) than that of the MAO-activated homogeneous system $\left(r r 93 \%, T_{\mathrm{m}} 152^{\circ} \mathrm{C}\right) .{ }^{7 \mathrm{~h}, 8 \mathrm{~h}, 28}$ Figure 3 shows ${ }^{13} \mathrm{C}$ NMR spectrum for the sPP formed with $\mathrm{MgCl}_{2}$-supported Ti-FI catalyst.

This result probably suggests that the immobilization of the Ti-FI catalyst onto $\mathrm{MgCl}_{2} / i-\mathrm{Bu}_{\mathrm{n}} \mathrm{Al}(\mathrm{OR})_{3-\mathrm{n}}$ does not suppress the site inversion process. The $T_{\mathrm{m}}$ of $155^{\circ} \mathrm{C}$ represents one of the highest known values for sPPs synthesized at room temperature. ${ }^{29}$ Mitani and Fujita have revealed that the sPPs formed with Ti-FI catalysts possess unique microstructures. The sPPs, formed from $\mathbf{1 0}$ and $\mathbf{2 3}$, with a significant amount of regioirregular units possess a blocklike structure involving long regioregular and short consecutive-regioirregular units. Conversely, the sPPs produced with 13-15, with a higher amount of regioirregular units, also have a blocklike structure, but it contains relatively short regioregular and isolated regioirregular units [Figure 4]. ${ }^{22 \mathrm{~b}}$

It should be pointed out that the $T_{\mathrm{m}} \mathrm{s}$ of sPPs arising from Ti-FI catalysts are higher than the values expected from the stereoregularity of the polymers obtained with metallocene catalysts. The differences in $T_{\mathrm{m}} \mathrm{s}$ probably stem from the blocklike structures of the polymers formed with Ti-FI catalysts. De Rosa and coworkers reported that the sPP produced with Ti-FI catalyst 22/MAO displays different crystalline microstructures, and thus different mechanical properties from the metallocene-made sPP of similar stereoregularity due to the presence of $m$ dyad defects derived from the chain-end control mechanism and defects of regioregularity in the FI-made sPP. ${ }^{30}$

Attempts have been made to achieve highly isospecific and living propylene polymerization with $C_{2}$ symmetric FI catalysts. Saito, Prasad and Fujita have shown that $\mathrm{Zr}$ - and Hf-FI catalysts combined with 
(a)

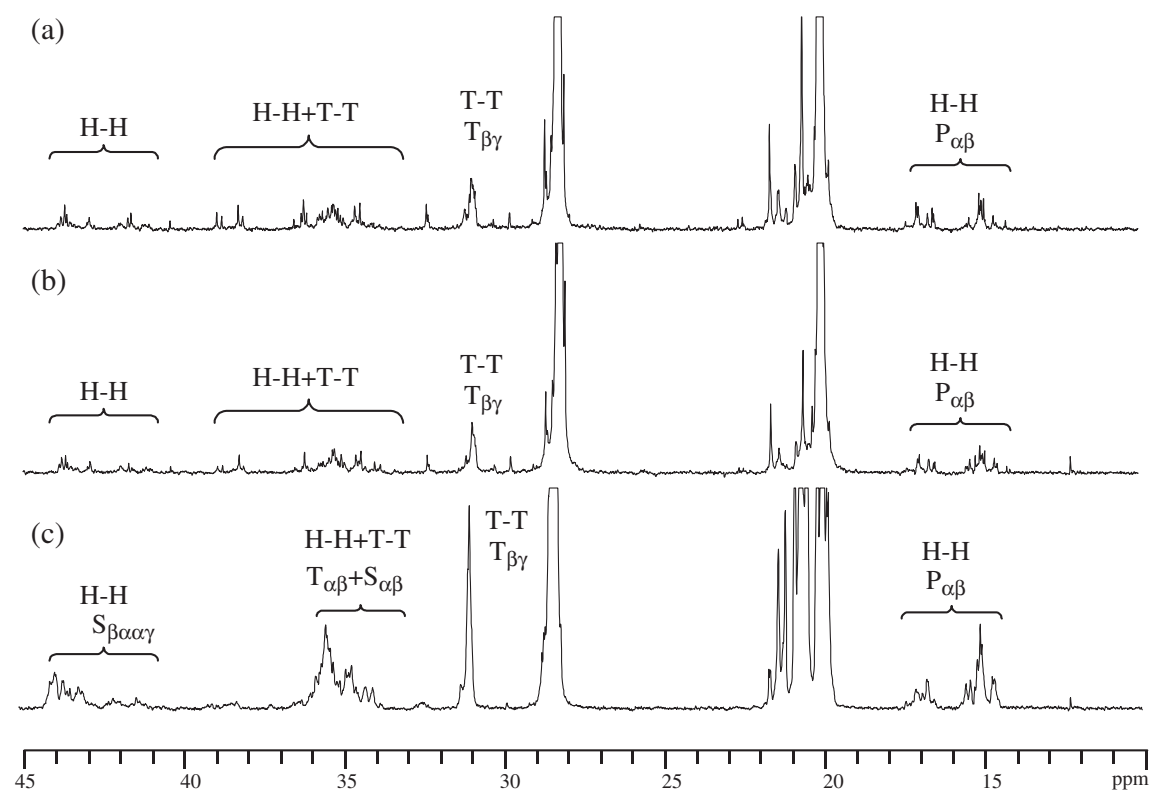

Figure 4. ${ }^{13} \mathrm{C}$ NMR spectra of the PPs formed with FI catalyst $\mathbf{1 0}$ (a), FI catalyst 23 (b) and FI catalyst 15 (c).

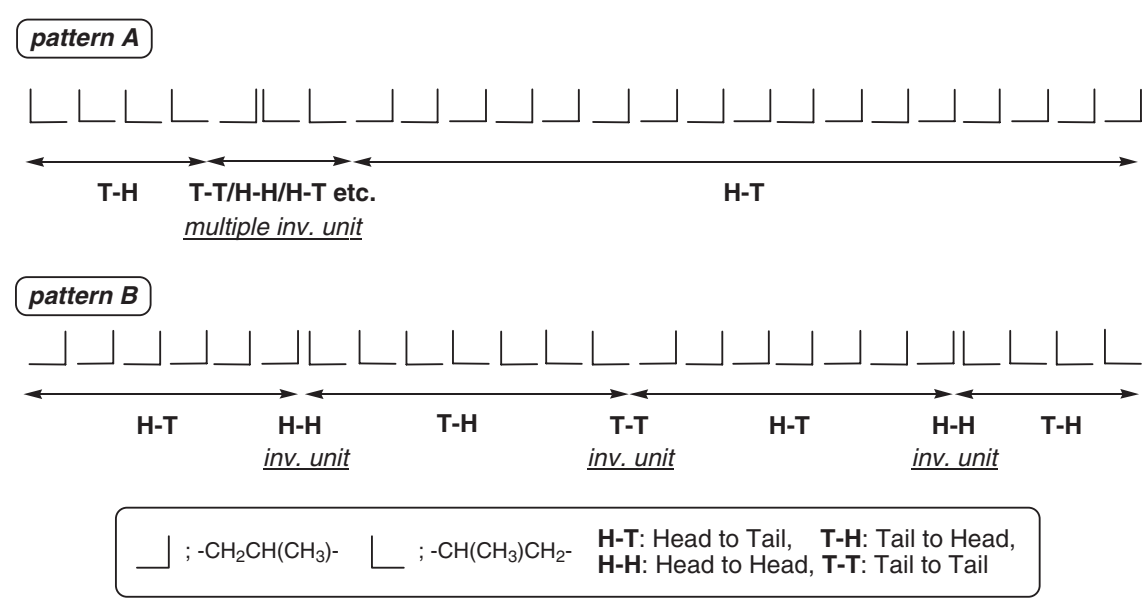

Figure 5. Regiosequence patterns of the PPs formed with fluorinated Ti-FI catalysts.

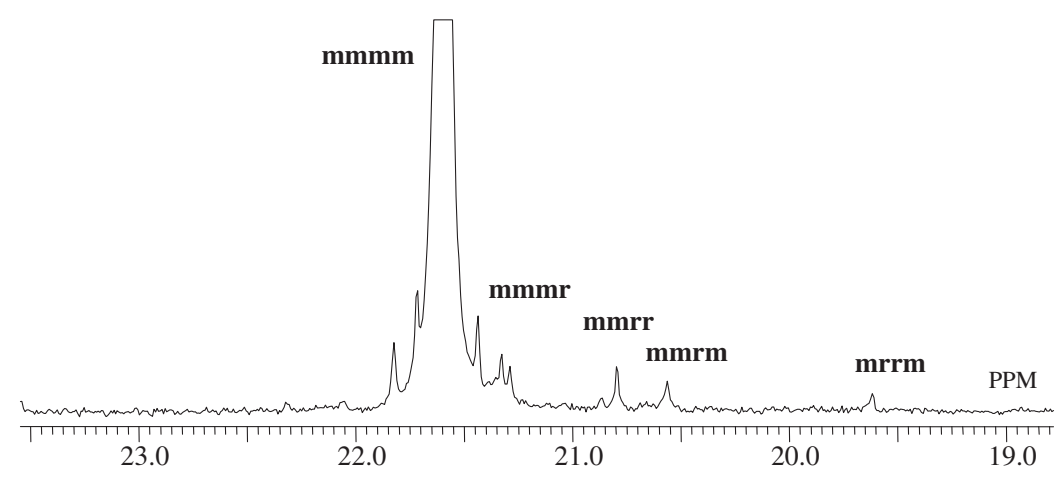

Figure 6. ${ }^{13} \mathrm{C}$ NMR spectrum for the iPP formed with FI catalyst 24/MAO.

$i-\mathrm{Bu}_{3} \mathrm{Al} /\left[\mathrm{CPh}_{3}\right]^{+}\left[\mathrm{B}\left(\mathrm{C}_{6} \mathrm{~F}_{5}\right)_{4}\right]^{-}$can produce highly isotactic, high molecular weight PPs via a site-control mechanism with 1,2-insertion, though in a nonliving fashion. ${ }^{31}$ For example, $24 / i-\mathrm{Bu}_{3} \mathrm{Al} /\left[\mathrm{CPh}_{3}\right]^{+}$-
$\left[\mathrm{B}\left(\mathrm{C}_{6} \mathrm{~F}_{5}\right)_{4}\right]^{-}$forms highly isotactic PP with extremely high $\mathrm{mmmm}(97 \%)$ and $T_{\mathrm{m}}\left(165^{\circ} \mathrm{C}\right)$ [Figure 6], both of which are comparable to those achieved by the best heterogeneous Ziegler/Natta catalysts. ${ }^{31 \mathrm{~b}}$ 
Recently, in association with MAO, Ti-Fi catalyst 25 having a phenyl group on the imine-C has been described by Mason and Coates to produce moderately isotactic and nearly monodisperse $\mathrm{PP}\left(0^{\circ} \mathrm{C}\right.$ polymerization; $m m m m 53 \%, T_{\mathrm{m}} 69.5^{\circ} \mathrm{C}, M_{\mathrm{n}} 27900, M_{\mathrm{w}} / M_{\mathrm{n}}$ $1.11)$, probably due to the suppression of a site-inversion process by the phenyl group on the imine-C. ${ }^{32}$ The corresponding Ti-FI catalysts possessing a sterically bulkier ortho-substituent (which is expected to form higher tacticity PPs) display practically no reactivity toward propylene. Thus, highly isospecific and living propylene polymerization with FI catalysts has not yet been achieved, which seems difficult when one considers the catalyst structure and performance relationships elucidated by Furuyama, Mitani and Fujita. $^{7 \mathrm{c}, \mathrm{d}, \mathrm{g}, 8 \mathrm{gg}, 10 \mathrm{~b}, 22}$ Very recently, Mazzeo and coworkers have described that phenoxy-aldimine-type Ti-FI catalysts having an I, $\mathrm{Br}$ or $\mathrm{Cl}$ ortho to the phenoxy-O (e.g., Ti-FI catalyst 26) with MAO produce prevailingly isotactic PPs with a $M_{\mathrm{w}} / M_{\mathrm{n}}$ of $c a .2$ via a site-control mechanism. ${ }^{13 a}$ Ishii and Fujita have also revealed that, upon activation with MAO, fluorinated Ti-FI catalyst 27 having a $\mathrm{CF}_{3}$ group ortho to the phenoxy-O promotes non-living propylene polymerization and provides iPP via a site-control mechanism. ${ }^{33}$

\section{FORMATION OF MONODISPERSE COPOLYMERS AND FUNCTIONALIZED (CO)POLYMERS}

Since the ortho-fluorinated Ti-FI catalysts can initiate highly controlled living polymerization of both ethylene and propylene, a wide variety of unique monodisperse copolymers have been created. Kojoh and Fujita have shown that Ti-FI catalyst $\mathbf{1 0}$ in combination with MAO efficiently catalyzes the living copolymerization of ethylene and propylene, giving access to copolymers with extremely narrow molecular weight distributions $\left(M_{\mathrm{w}} / M_{\mathrm{n}} 1.07-1.13\right.$, propylene content $15-48 \mathrm{~mol} \%) .{ }^{34}$ Weiser and Mülhaupt have prepared Ti-FI catalyst 11, upon activation with MAO, which displays improved incorporation ability toward propylene, and produces ethylene/propylene copolymers with compositions covering the entire feasible composition range (propylene content up to $93 \mathrm{~mol} \%) .{ }^{19}$

Monodisperse ethylene/higher $\alpha$-olefin copolymers are also available with fluorinated Ti-FI catalysts having sterically less encumbered substituents ortho to the phenoxy-O. For example, Furuyama and Fujita have demonstrated that Ti-FI catalyst $\mathbf{1 5}$ having a $\mathrm{H}$ ortho to the phenoxy-O combined with MAO forms ethylene/higher $\alpha$-olefin copolymers with the higher $\alpha$-olefin contents of $23 \mathrm{~mol} \%$ (1-hexene), $21 \mathrm{~mol} \%$
Table III. Ethylene/higher $\alpha$-olefin copolymerization with FI catalyst $15 / \mathrm{MAO}^{\mathrm{a}}$

\begin{tabular}{lcccc}
\hline -olefin & $\begin{array}{c}\text { yield } \\
(\mathrm{g})\end{array}$ & $\begin{array}{c}M_{\mathrm{n}} \mathrm{b} \\
\left(\times 10^{-3}\right)\end{array}$ & $M_{\mathrm{w}} / M_{\mathrm{n}} \mathrm{b}^{\mathrm{b}}$ & $\begin{array}{c}\alpha \text {-olefin } \\
\text { content } \\
(\mathrm{mol} \%)\end{array}$ \\
\hline 1-hexene & 0.21 & 54.2 & 1.07 & 22.6 \\
1-octene & 0.21 & 60.5 & 1.09 & 20.8 \\
1-decene & 0.22 & 72.0 & 1.10 & 14.3 \\
\hline
\end{tabular}

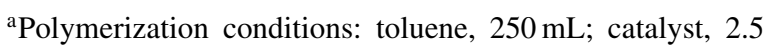
$\mu \mathrm{mol}$; MAO, $1.25 \mathrm{mmol}$; ethylene, $100 \mathrm{~L} / \mathrm{h}$; $\alpha$-olefin, $50 \mathrm{ml}$; time, $5 \mathrm{~min}$; temperature, $25^{\circ} \mathrm{C}$. ${ }^{\mathrm{b}}$ Determined by GPC using polyethylene calibration. ${ }^{\mathrm{c}}$ Determined by ${ }^{1} \mathrm{H}$ NMR.

(1-octene) and $14 \mathrm{~mol} \%$ (1-decene), respectively [Table III]. ${ }^{20}$

Using the propensity for secondary insertion of TiFI catalysts, which was first elucidated by researchers at Mitsui Chemicals, ${ }^{11 \mathrm{c}}$ characteristic monodisperse polymers can be prepared. For example, Ti-FI catalyst 22 with MAO activation was reported by Hustad and Coates to polymerize 1,5-hexadiene to form poly(3vinyl tetramethylene-co-methylene-1,3-cyclopentane) through insertion and isomerization polymerization $\left(M_{\mathrm{n}} 268000, M_{\mathrm{w}} / M_{\mathrm{n}} 1.27,3\right.$-vinyl tetramethylene $37 \mathrm{~mol} \%$, methylene-1,3-cyclopentane $63 \mathrm{~mol} \%$ ). ${ }^{35}$ Additionally, the copolymerization of propylene with 1,5-hexadiene using Ti-FI catalyst 22 resulted in the formation of poly(propylene-co-3-vinyl tetramethylene-co-methylene-1,3-cyclopentane) having the highly syndiotactic nature of the PP domains. Since these 1,5-hexadiene-derived polymers contain pendant vinyl groups, the polymers can be valuable intermediates for the synthesis of functionalized polymers and block copolymers. For example, the vinyltetramethylene units in the copolymer have been shown by Mather and Coates to undergo a cross-metathesis reaction with functionalized olefinic monomers catalyzed by a Ru carbene for functionalization of the copolymer. ${ }^{36}$

Alternatively, Fujita and Coates have described that polymerization of ethylene and cyclopentene using 22/MAO produces copolymers with isolated, cis-1,2-cyclopentane units (cyclopentene content up to $47 \mathrm{~mol} \%$ ). The nearly alternating copolymer with a cyclopentene content of $47 \mathrm{~mol} \%$ possesses an atactic nature. ${ }^{12 b}$

In addition to a wide variety of monodisperse (co)polymers, Makio and Fujita have indicated that chainend functionalized monodisperse (co)polymers including telechelic polymers are available with the fluorinated Ti-FI catalysts if a functionalized monomer [e.g., $\mathrm{CH}_{2}=\mathrm{CH}-\left(\mathrm{CH}_{2}\right)_{\mathrm{n}}-\mathrm{OSiMe}_{3}, \mathrm{CH}_{2}=\mathrm{CH}-\left(\mathrm{CH}_{2}\right)_{\mathrm{n}}-$ $\left.\mathrm{OAlMe}_{2}, \mathrm{Ch}_{2}=\mathrm{CH}-\left(\mathrm{CH}_{2}\right)_{\mathrm{n}}-\mathrm{N}\left(\mathrm{SiMe}_{3}\right)_{2}\right]$ is used during the initiation and/or termination step(s). For example, 10 with MAO furnished both PE- and sPP-based monodisperse polymers bearing terminal 
Table IV. Monodisperse (co)polymers created by Ti-FI catalysts/MAO

polyethylene

polypropylene (atactic to highly syndiotactic)

moderately isotactic polypropylene

poly(ethylene-co-propylene)

poly(ethylene-co-1-hexene)

poly(ethylene-co-1-octene)

poly(ethylene-co-1-decene)

poly(ethylene-co-cyclopentene)

poly(ethylene-co-norbornene)

poly(methylene-1,3-cyclopentane-co-3-vinyl tetramethylene)

Zn-terminated polyethylene

$-\mathrm{NH}_{2}$ and/or $-\mathrm{OH}$ functional groups [e.g., HO-sPP$\left.\mathrm{OH}, M_{\mathrm{n}} 9560, M_{\mathrm{w}} / M_{\mathrm{n}} 1.08\right]$. The functionalized $s \mathrm{PPs}$ showed $T_{\mathrm{m}} \mathrm{s}$ in the range of $142-145^{\circ} \mathrm{C}$, indicative of a highly syndiotactic nature. ${ }^{7 \mathrm{~d}, 10 \mathrm{~b}, 37}$ The functionalized monodisperse (co)polymers described above have the potential to be excellent compatibilizers, surface modifiers and well-defined macromonomers for the synthesis of block and graft copolymers.

\section{MECHANISTIC FEATURES OF LIVING POLYMERIZATION WITH FLUORINATED TI-FI CATALYSTS}

As introduced so far, the well-established experimental results suggest that the presence of the ortho$\mathrm{F}$ accounts for living ethylene polymerization and that steric factors do not play a salient role in achieving living polymerization, meaning that the ortho-F is most probably involved electronically in the realization of living ethylene polymerization. Situations seem to be the same for living propylene polymerization with fluorinated Ti-FI catalysts, on the basis of experimental data.

It was believed, at first, that the living nature originated from the stabilization of the Ti center by the ortho-F through electronic interaction. Mitani, Nakano and Fujita have reported though that DFT calculations on an active species derived from 10/MAO for ethylene polymerization indicate that there was virtually no interaction between the Ti metal and the ortho-F (Ti/ortho-F distance, ca. $4 \AA$ ), and surprisingly the ortho-F interacted attractively with a $\beta-\mathrm{H}$ on a growing polymer chain (ortho- $\mathrm{F} / \beta$-H distance $2.28 \AA$, electrostatic energy $27 \mathrm{~kJ} /$ mole, Figure 7). ${ }^{10,18}$

In response to the attractive interaction present between the ortho-F and the $\beta-\mathrm{H}$, a degree of $\mathrm{C}-\mathrm{H}_{\beta}$ bond elongation $(1.11 \AA$ ) was indicated by the calculations. Similar calculation results were obtained for propylene polymerization independent of the insertion mode of propylene. Therefore, it was proposed that the attractive interaction, which is expected to effectively

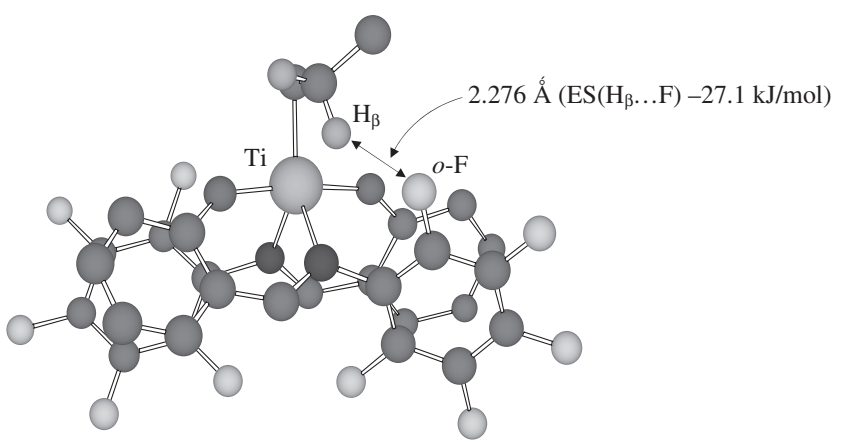

Figure 7. Calculated structure of an active species derived from FI catalyst $10 .{ }^{t} \mathrm{Bu}$ groups are omitted for clarity.

curtail $\beta-\mathrm{H}$ transfer to the central metal and/or an incoming monomer, is responsible for the unprecedented living behavior.

However, for living propylene polymerization with fluorinated Ti-FI catalysts, it was proposed by Talarico and coworkers that the effect of the ortho-F is primarily steric based on $\mathrm{QM} / \mathrm{MM}$ calculation results. ${ }^{38}$ As described, the well-established experimental data indicates that only a single ortho-F is a requirement for the living polymerization of propylene as well as ethylene. ${ }^{18,25}$ This fact probably suggests that steric factors do not play a key role in the achievement of living propylene polymerization, since, for the single ortho-F Ti-FI catalyst, the 2-fluorophen$\mathrm{yl}$ group on the imine- $\mathrm{N}$ can rotate to evade steric hindrance which may suppress chain transfer reactions. The discrepancy between the calculations and the experimental data seems to originate from the fact that the calculations are not taking into consideration the solvent and co-catalyst influence though the solvent and the co-catalyst employed are known to have a significant influence on the polymerization behavior of Ti-FI catalysts (activity, molecular weight, molecular weight distribution). ${ }^{7,10,12 a, d, 22}$

Kui and Chan reported the first NMR and X-ray structural evidence for an attractive interaction between an $\mathrm{F}$ in the ligand and an $\mathrm{H}$ of a benzyl group attached to group 4 metal catalysts. ${ }^{39 a}$ Additionally, by a neutron diffraction study, Chan, Cole and their coworkers elucidated the structural parameters of the $\mathrm{F} / \mathrm{H}$ interaction $(\mathrm{F} / \mathrm{H}$ distance $2.572(6)$ and 2.607(5) $\AA, \mathrm{F} / \mathrm{H}$ angle 103.3(4) and 108.2(3), indicating the presence of the attractive interaction between the $\mathrm{F}$ in the ligand and the $\mathrm{H}$ of the alkyl group attached to the group 4 metal. $^{39 \mathrm{~b}}$ These results demonstrate that the $\mathrm{F} / \mathrm{H}$ interaction suggested by DFT calculations is experimentally feasible.

It should be pointed out that Suzuki and Fujita have reported on a structurally related bis(imine-phenoxy)Ti complex 28 having a $\mathrm{C}_{6} \mathrm{~F}_{5}$ on the imine- $\mathrm{N}$ with MAO activation, which does not promote living ethyl- 
ene polymerization. ${ }^{40}$ Interestingly, DFT calculations have indicated that there is virtually no interaction between the ortho-F and the $\beta-\mathrm{H}$ (ortho- $\mathrm{F} / \beta-\mathrm{H}$ distance $3.66 \AA$ ).

Based on the results and discussions described so far, Furuyama and Fujita have concluded that the steric bulk provided by the ortho-F does not play an important role and that the attractive non-bonding interaction of the ortho-F with the $\beta$-H of the growing polymer chain is responsible for the unprecedented living polymerization, representing the first example of an attractive interaction between the ligand and other components in a catalyst system, which dramatically enhances catalyst performance. ${ }^{10 \mathrm{~b}}$

In a study on the solution structure of the active species in fluorinated Ti-FI catalysts by ${ }^{1} \mathrm{H}$ NMR spectroscopy, Makio and Fujita observed, for the first time, the formation of cationic species $\mathrm{L}_{2} \mathrm{Ti}^{+} \mathrm{Me}$ (L: phenoxy-imine ligand) derived from 10/MAO and its living propagating species. ${ }^{41}$ Additionally, Bryliakov and Talsi characterized cationic species formed from Ti-FI catalyst $\mathbf{1 0}$ with $\mathrm{MAO}$ or $\mathrm{AlMe}_{3} /$ $\left[\mathrm{CPh}_{3}\right]^{+}\left[\mathrm{B}\left(\mathrm{C}_{6} \mathrm{~F}_{5}\right)_{4}\right]^{-}$by ${ }^{1} \mathrm{H},{ }^{19} \mathrm{~F}$, and ${ }^{13} \mathrm{C}$ NMR and electron paramagnetic resonance (EPR) spectroscopy. ${ }^{13 \mathrm{j}}$ They observed the generation of outer-sphere ion pairs and the formation of the polymeryl species after reaction with ethylene.

Makio and Fujita have successfully synthesized dimethyl complexes of the fluorinated Ti-FI catalysts, which exhibit an essentially octahedrally coordinated Ti center and $C_{2}$ symmetry, with a cis-O, cis- $\mathrm{N}$, cismethyl disposition. ${ }^{42}$ The Ti-FI dimethyl complexes can readily be activated with $\mathrm{B}\left(\mathrm{C}_{6} \mathrm{~F}_{5}\right)_{3}$ or $\left[\mathrm{CPh}_{3}\right]^{+}$$\left[\mathrm{B}\left(\mathrm{C}_{6} \mathrm{~F}_{5}\right)_{4}\right]^{-}$to form a methyl cationic species. The addition of ethylene to the cationic species allows room temperature observation of the living propagating species, which displays ${ }^{1} \mathrm{H}$ NMR peaks centered at 1.45 and $2.88 \mathrm{ppm}$ that are assigned to the diastereotopic $\alpha$-methylene protons connected to the Ti metal. These results further confirm the highly controlled, thermally robust living nature of the fluorinated Ti-FI catalysts. Additional studies will probably give further insight into the polymerization mechanism, including the ortho- $\mathrm{F} / \beta-\mathrm{H}$ interaction suggested by the theoretical work and configurational fluxionality of catalytically active species.

Due of the inherent and highly controlled living nature and the elaborate catalyst design work focusing on the substitution pattern of F's as well as the substituent ortho to the phenoxy-O, Mitani and Fujita have successfully developed Ti-FI catalysts 29 and 30, that catalytically produce living polymers [monodisperse PE, Zn-terminated PE, PE- $b$-poly(ethyleneco-propylene)] in the presence of an appropriate chain transfer agent (e.g., $\left.\mathrm{H}_{2}, \mathrm{ZnEt}_{2}\right) .{ }^{10,43}$

\section{BLOCK COPOLYMERS CREATED BY FLUORINATED TI-FI CATALYSTS}

One of the most attractive features of a living olefin polymerization catalyst lies in its capability to form well-defined polyolefinic block copolymers. As introduced, fluorinated Ti-FI catalysts can efficiently synthesize a wide array of polyolefins including PE, PP with an atactic to highly syndiotactic nature, ethylene/propylene copolymers, ethylene/higher $\alpha$-olefin copolymers, and ethylene/cyclopentene copolymers in a living fashion. Thus, the fluorinated Ti-FI catalysts allow the production of block copolymers consisting of semicrystalline and amorphous polyolefin segments such as those listed above.

Mitani, Kojoh, and Fujita have prepared a wide variety of ethylene/propylene di- and multiblock copolymers, which include PE- $b$-poly(ethylene-co-propylene), PE- $b$-sPP, sPP- $b$-poly(ethylene-co-propylene), poly(ethylene- $c o$-propylene) $)_{1}-b$-poly(ethylene-co-propylene $)_{2}, \quad$ PE- $b$-poly(ethylene-co-propylene)- $b$-PE, and PE- $b$-poly(ethylene-co-propylene)- $b$-sPP, using 10 with MAO activation. ${ }^{9}, 10,18,34$ Most of the block copolymers created by Mitani et al. were inaccessible prior to their work. A sPP- $b$-poly(ethylene-co-propylene) similar to that described above by Mitani et al. has been prepared by Tian and Coates using 22/MAO. ${ }^{12 \mathrm{a}}$

Weiser and Mülhaupt obtained high molecular weight PE- $b$-poly(ethylene-co-propylene) with a variety of propylene contents and block lengths (PE block, $400000<M_{\mathrm{n}}<1100000$, ethylene/propylene copolymer block, $150000<M_{\mathrm{n}}<900000 ; T_{\mathrm{m}} 122$ $134^{\circ} \mathrm{C}, T_{\mathrm{g}}<-30^{\circ} \mathrm{C}$ ), using Ti-FI catalyst 11 which had iodines in the ligand. ${ }^{19}$ The characterization of these high molecular weight block copolymers was done by means of atomic force microscopy (AFM), crystallization fractionation (CRYSTAF) data and high temperature chromatographic elution, thus giving the experimental evidence that no homo-PE and less than $5 \%$ of ethylene/propylene copolymers are formed as by-products, suggesting the highly controlled living nature of the catalyst. Ethylene- and higher $\alpha$-olefin-based block copolymers are also available with Ti-FI catalysts/MAO. Furuyama and Fujita prepared a series of PE- $b$-poly(ethylene-co-1-hexene) with various 1-hexene contents and ethylene/1hexene copolymer block lengths (PE block, $M_{\mathrm{n}}$ 38300 , ethylene/1-hexene copolymer block, $23200<$ $M_{\mathrm{n}}<82700$, 1-hexene content 8-29 mol \%; $T_{\mathrm{m}} 117-$ $130^{\circ} \mathrm{C}$ ), using Ti-FI catalyst $\mathbf{1 4}$, which possesses enhanced incorporation ability for sterically encumbered monomers. ${ }^{20}$

The block copolymers introduced above, in particular, semicrystalline PE or sPP and ethylene $/ \alpha$-olefin 
Table V. Block copolymers created by Ti-FI catalysts/MAO

\begin{tabular}{l}
\hline PE- $b$-PP \\
PE- $b$-PS \\
PE- $b$-poly(ethylene-co-propylene) \\
PE- $b$-poly(ethylene-co-1-hexene) \\
PE- $b$-poly(ethylene-co-cyclopentene) \\
PP- $b$-poly(ethylene- $c o$-propylene) \\
PP- $b$-poly(propylene-co-methylene-1,3-cyclopentane-co-3-vinyl \\
tetramethylene) \\
poly(ethylene-co-propylene) $)_{1}-b$-poly(ethylene-co-propylene) ${ }_{2}$ \\
poly(ethylene-co-propylene)- $b$-PS \\
poly(ethylene-co-propylene)- $b$-poly(ethylene-co-norbornene) \\
poly(methylene-1,3-cyclopentane-co-3-vinyl tetramethylene)- \\
$b$-poly(ethylene- $c o$-norbornene) \\
PE- $b$-poly(ethylene-co-propylene)- $b$-PE \\
PE- $b$-poly(ethylene-co-propylene)- $b$-PP \\
PE-b-poly(ethylene- $c o$-cyclopentene) $)_{1}$ - $b$-poly(ethylene- $c o$ - \\
cyclopentene $)_{2}$
\end{tabular}

copolymer-based block copolymers have a wide array of applications because their macroscopic properties can vary from elastomeric to plastic depending on the volume fraction of the ethylene/ $\alpha$-olefin copolymer block. ${ }^{9,10,18,20,34}$

Additionally, using 22/MAO sPP-b-poly(propylene-co-methylene-1,3-cyclopentane-co-3-vinyl tetramethylene) from propylene and 1,5-hexadiene, and PE- $b$-poly(ethylene-co-pentene) have been prepared by Hustad, Fujita, and Coates. ${ }^{12 b, 35}$ Very recently, Yoon and Thomas have reported on the synthesis of poly(ethylene-co-propylene)- $b$-poly(ethylene-co-norbornene) and poly(methylene-1,3-cyclopentane-co-3vinyl tetramethylene)- $b$-(ethylene-co-norbornene), which display a partial one-dimensional photonic band gap with excellent optical transparency. ${ }^{44}$

Although Michiue and Fujita described that $\mathrm{Ti}, \mathrm{Zr}$ and Hf-FI catalysts convert styrene to $\mathrm{SPS},{ }^{45}$ the synthesis of olefin/styrene block copolymers was not reported until recently. Weiser and Mülhaupt have prepared PE- $b$-PS and poly(ethylene-co-propylene)- $b$-PS using Ti-FI catalyst 11/MAO for the first time. ${ }^{19}$ With chromatographic and TEM analysis, they have revealed the formation of the blends of the desired block copolymers and homo-PE (or ethylene/propylene copolymers). The direct olefin/styrene block copolymer synthesis with a Ti-FI catalyst represents an attractive, new one-pot route to styrenic block copolymers which are commercially prepared by anionic styrene/diene block copolymerization, followed by the hydrogenation of the resultant polymer.

In summary, fluorinated Ti-FI catalysts developed by researchers at Mitsui Chemicals have led to the synthetic creation of block copolymers from a wide array of olefinic monomers, including ethylene, propylene, 1-hexene, cyclopentene and styrene.

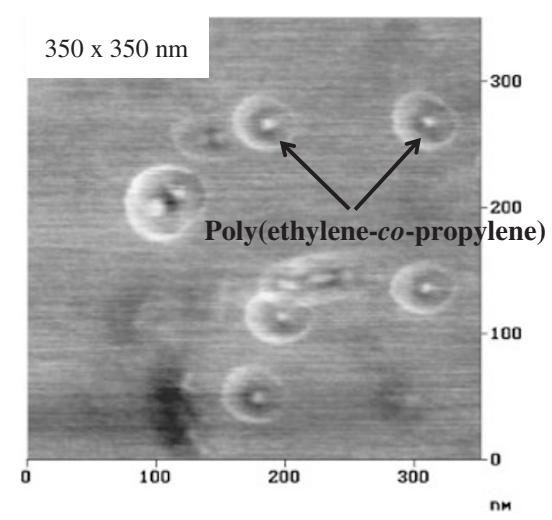

Figure 8. AFM image of PE- $b$-poly(ethylene-co-propylene).

\section{MORPHOLOGIES AND MATERIAL PROPERTIES OF THE LIVING POLYMERS FORMED WITH FLUORINATED TI-FI CATALYSTS}

Since the block copolymers formed from the fluorinated Ti-FI catalysts are new materials, there has been tremendous interest in their morphologies and material properties, in addition to their novel polyolefin chain architectures. With AFM analysis, Ono and Fujita have elucidated that PE- $b$-poly(ethylene-copropylene) that was made with $10 / \mathrm{MAO}$, on a mica surface can exist as an individual molecule in which a PE lamella is covered with an amorphous ethylene/propylene copolymer. ${ }^{46}$

In the AFM image shown in Figure 8 [total $M_{\mathrm{n}} 38100$, PE block $M_{\mathrm{n}} 8700, M_{\mathrm{w}} / M_{\mathrm{n}} 1.12$; propylene content of ethylene/propylene copolymer block $39.9 \mathrm{~mol} \%$ ], the central spot corresponds to a PE lamella and the surrounding part is an amorphous ethylene/propylene copolymer. The size of the central spot (PE lamella) is estimated to be $2.5-5.0 \mathrm{~nm} \times 5.0-10.0 \mathrm{~nm}$. Interestingly, the block copolymer possesses a tendency to assemble one to another to form a needle-like structure.

AFM analyses of PE- $b$-poly(ethylene-co-propylene)s with varying propylene contents of the copolymer segments (8-70 mol \%) made by $11 /$ MAO were performed by Weiser and Mülhaupt, who observed that the morphology of the block copolymers changes significantly depending on the propylene contents. ${ }^{19}$ For example, the block copolymer with a propylene content of $8 \mathrm{~mol} \%$ displays a rather micellar domain of the soft "rubbery" phase (domain size 150-300 nm) [Figure 9(a)], whereas that with a propylene content of $70 \mathrm{~mol} \%$ exhibits the inverse phase with micellar PE structure (diameter of PE micelles are below $100 \mathrm{~nm}$ ) [Figure 9(b)].

Unique thermodynamic behavior of PE- $b$-poly(ethylene-co-1-hexene)s formed with 14/MAO was reported by Furuyama and Fujita. ${ }^{20}$ They revealed us- 
(a)

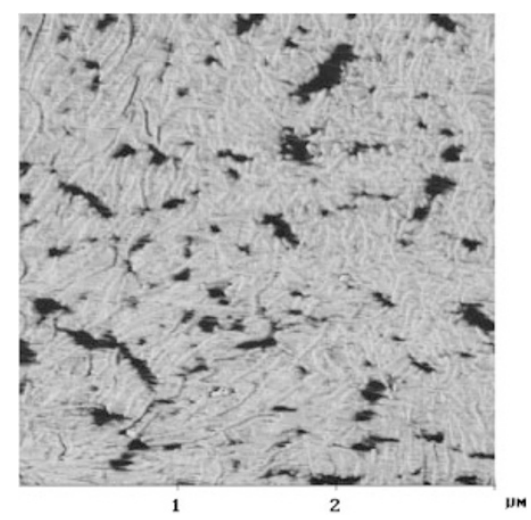

(b)

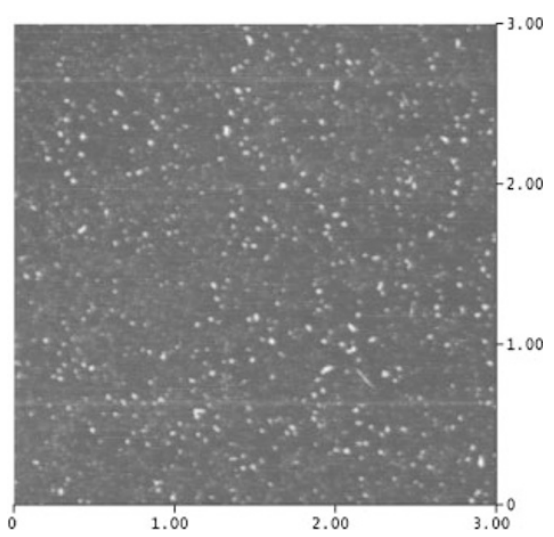

Figure 9. AFM images of PE- $b$-poly(ethylene-co-propylene)s with propylene contents of $8 \mathrm{~mol} \%$ (a) and $70 \mathrm{~mol} \%$ (b).

(A)

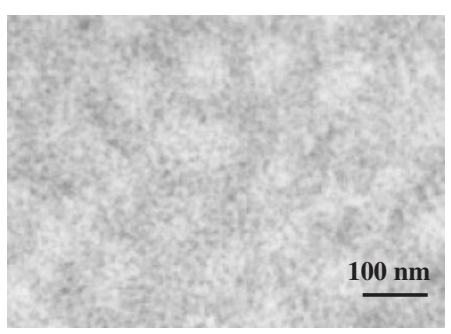

(B)

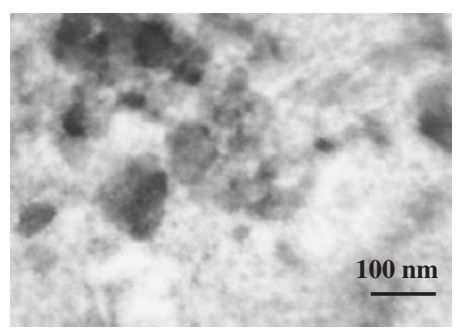

Figure 10. TEM micrographs of (A) sPP-b-poly(ethylene-co-propylene) and (B) sPP/poly(ethylene-co-propylene) blend polymer (blend conditions; toluene, $100^{\circ} \mathrm{C}, 1 \mathrm{~h}$ ).

ing differential scanning calorimetry (DSC) that the block copolymers having a higher molecular weight copolymer segment exhibit lower $T_{\mathrm{m}} \mathrm{s}$ and smaller enthalpies of fusion, which is consistent with the proposal that the crystallization process of the PE segment is disturbed by the presence of the chemically linked ethylene/1-hexene copolymer segment, providing thinner lamellar crystals and lower crystallinity. Furuyama and Fujita also demonstrated that an increase in the 1-hexene content of the copolymer segment results in an increase in $T_{\mathrm{m}}$, suggesting that a copolymer segment with a higher 1-hexene content (a softer copolymer segment) has less effect on the crystallization process of the PE segment, which is probably because of the reduced affinity between the two segments.

Kojoh and Fujita studied the morphology differences between sPP- $b$-poly(ethylene-co-propylene) and the corresponding $\mathrm{sPP} /$ poly(ethylene-co-propylene) blend polymer using TEM. ${ }^{34}$ The TEM micrograph of the block copolymer [Figure 10(A)] displays well-defined and regular morphology compared to that of the blend polymer [Figure 10(B)]. Nano-phase separation of sPP domains ( $c a .10 \mathrm{~nm}$ in diameter) embedded into the poly(ethylene-co-propylene) matrix was visible.

Kramer, Coates and their coworkers have also in- vestigated the morphology and thermodynamic behavior of sPP- $b$-poly(ethylene-co-propylene) by using TEM and DSC. ${ }^{47}$ With TEM analysis, they have observed a number of ordered morphologies, which include cylindrical, lamellar, and hexagonally perforated layer morphologies; the latter being most often observed in spite of the fact that it is anticipated to be metastable. Additionally, they have revealed that the sPP crystallization and peak melting temperatures ( $T_{\mathrm{c}}$ and $T_{\mathrm{m}}$ ) determined by DSC show little correlation with either block copolymer morphology or the state of block copolymer melt phase (ordered or disordered) but rather increase with a decrease in the total molecular weight of the block copolymer.

Using small-angle neutron scattering (SANS), Radulescu and coworkers have shown that $s \mathrm{PP}-b$ poly(ethylene-co-propylene) formed with 22/MAO crystallizes in very large, one-dimensional, supramolecular aggregates with radii between 44 and $80 \mathrm{~nm}$ containing substructures, and are formed due to selfassembling at a larger scale. ${ }^{48}$

The tensile properties of the PE- $b$-poly(ethyleneco-1-hexene) that were made with Ti-FI catalyst 14/ MAO $\left(M_{\mathrm{n}} 79900, M_{\mathrm{w}} / M_{\mathrm{n}} 1.29,1\right.$-hexene content $6 \mathrm{~mol} \%$ ) were studied by Furuyama and Fujita. ${ }^{20}$ The results are summarized in Table VI, which in- 
Table VI. Results of the tensile test of compression-molded films

\begin{tabular}{cccccccc}
\hline & $\begin{array}{c}M_{\mathrm{n}}{ }^{\mathrm{a}} \\
\left(\times 10^{3}\right)\end{array}$ & $\begin{array}{c}E_{\mathrm{m}}{ }^{\mathrm{b}} \\
(\mathrm{MPa})\end{array}$ & $\begin{array}{c}\sigma_{\mathrm{y}}^{\mathrm{b}} \\
(\mathrm{MPa})\end{array}$ & $\begin{array}{c}\varepsilon_{\mathrm{y}}{ }^{\mathrm{b}} \\
(\%)\end{array}$ & $\begin{array}{c}\sigma_{\mathrm{b}} \mathrm{b} \\
(\mathrm{MPa})\end{array}$ & $\begin{array}{c}\varepsilon_{\mathrm{b}}{ }^{\mathrm{b}} \\
(\%)\end{array}$ & $\begin{array}{c}1-\text { hexene } \\
\text { content } \\
(\mathrm{mol} \%)\end{array}$ \\
\hline $\begin{array}{c}\text { PE- } b \text {-poly(ethylene-co-1-hexene) } \\
\text { poly(ethylene-co-1-hexene) }\end{array}$ & 79.9 & 119 & 7.59 & 13.9 & 26.0 & 488 & 4.3 \\
\hline
\end{tabular}

${ }^{\mathrm{a}}$ Determined by GPC using polyethylene calibration. ${ }^{\mathrm{b}} E_{\mathrm{m}}=$ elastic modulus, $\sigma_{\mathrm{y}}=$ stress at the yield point, $\varepsilon_{\mathrm{y}}=$ strain at the yield point, $\sigma_{\mathrm{b}}=$ stress at the break point, $\varepsilon_{\mathrm{b}}=$ strain at the break point.

cludes the tensile properties of the corresponding random copolymer as a comparison. The block copolymer displays an extensibility of $488 \%$, which is superior to that of the random copolymer. Moreover, the block copolymer exhibits a greater degree of toughness, $119 \mathrm{MPa}$, compared to the random copolymer.

The tensile properties that were elucidated by Furuyama and Fujita indicate that the block copolymer possesses a good combination of extensibility and toughness, probably because of the co-presence of tough crystalline PE and soft amorphous ethylene/1-hexene copolymer segments in the same molecule.

\section{CONCLUSION}

The advent of fluorinated bis(phenoxy-imine)Ti complexes (fluorinated Ti-FI catalysts) for living olefin polymerizations has made a significant impact on polymerization catalysis and polymer synthesis. On the basis of the well-established experimental data together with DFT calculations, it has been proposed that the unprecedented living polymerizations catalyzed by fluorinated Ti-FI catalysts result from an attractive interaction of the ortho-F with the $\beta-\mathrm{H}$ of the growing polymer chain, thus stabilizing it against termination. Fluorinated Ti-FI catalysts are capable of mediating the highly controlled, thermally robust living polymerization of ethylene. Additionally, these $\mathrm{C}_{2}$-symmetric FI catalysts can induce highly syndiospecific living propylene polymerization via a chainend control mechanism with unusual 2,1-monomer insertion, including a site-inversion process. Moreover, these catalysts are capable of promoting the living copolymerizations of ethylene/propylene, ethylene/ higher $\alpha$-olefins, ethylene/cyclopentene, and others. Therefore, the fluorinated Ti-FI catalysts have enabled us to prepare well-defined block copolymers such as PE- $b$-poly(ethylene-co-1-hexene), sPP- $b$-poly(ethylene-co-propylene), PE- $b$-poly(ethylene-co-cyclopentene) and PE- $b$-PS; highly syndiotactic monodisperse PPs, monodisperse high and ultra-high molecular weight PEs; and ethylene-based copolymers and functionalized (co)polymers from the monomers and/or monomer combinations described above. Some of the FI living polymers have been demonstrated to exhibit unique morphologies and useful material properties, indicative of their tremendous potential.

\section{REFERENCES}

1. M. Szwarc, J. Polym. Sci., Part A: Polym. Chem., 36, IX (1998).

2. a) Y. Doi, M. Takada, and T. Keii, Bull. Chem. Soc. Jpn., 52, 1802 (1979).

b) Y. Doi, S. Ueki, and T. Keii, Macromolecules, 12, 814 (1979).

c) Y. Doi, S. Ueki, and T. Keii, Makromol. Chem., 180, 1359 (1979).

d) Y. Doi and T. Keii, Adv. Polym. Sci., 73/74, 201 (1986). e) Y. Doi, N. Tokuhiro, and K. Soga, Makromol. Chem., Makromol. Chem. Phys., 190, 643 (1989).

3. For review: a) H. H. Brintzinger, D. Fisher, R. Mülhaupt, B. Rieger, and R. M. Waymouth, Angew. Chem., Int. Ed., 34, 1143 (1995).

b) M. Bochmann, J. Chem. Soc., Dalton Trans., 255 (1996). c) A. L. McKnight and R. M. Waymouth, Chem. Rev., 98, 2587 (1998).

d) G. J. P. Britovsek, V. C. Gibson, and D. F. Wass, Angew. Chem., Int. Ed., 38, 428 (1999).

e) S. D. Ittel, L. K. Johnson, and M. Brookhart, Chem. Rev., 100, 1169 (2000).

f) Z. Hou and Y. Wakatsuki, Coord. Chem. Rev., 231, 1 (2002).

g) H. Hagen, J. Boersma, and G. van Koten, Chem. Soc. Rev., 31, 357 (2002).

h) S. Gambarotta, Coord. Chem. Rev., 237, 229 (2003).

i) V. C. Gibson and S. K. Spitzmesser, Chem. Rev., 103, 283 (2003).

j) Y. Suzuki, H. Terao, and T. Fujita, Bull. Chem. Soc. Jpn., 76, 1493 (2003).

k) J. Gromada, J.-F. Carpentier, and A. Mortreux, Coord. Chem. Rev., 248, 397 (2004).

1) D. W. Stephan, Organometallics, 24, 2548 (2005).

m) W. Wang, T. Tanaka, M. Tsubota, M. Fujiki, S. Yamanaka, and K. Nomura, Adv. Synth. Catal., 347, 433 (2005).

n) P. D. Bolton and P. Mountford, Adv. Synth. Catal., 347, 355 (2005).

4. a) H. Yasuda, M. Furo, H. Yamamoto, A. Nakamura, S. Miyake, and N. Kibino, Macromolecules, 25, 5115 (1992). b) K. Mashima, S. Fujikawa, and A. Nakamura, J. Am. Chem. Soc., 115, 10990 (1993).

c) M. Brookhart, J. M. DeSimone, B. E. Grant, and M. J. 
Tanner, Macromolecules, 28, 5378 (1995).

d) J. D. Scollard and D. H. McConville, J. Am. Chem. Soc., 118, 10008 (1996).

e) C. M. Killian, D. J. Tempel, L. K. Johnson, and M. Brookhart, J. Am. Chem. Soc., 118, 11664 (1996).

f) R. Baumann, W. M. Davis, and R. R. Schrock, J. Am. Chem. Soc., 119, 3830 (1997).

g) Y. M. Jeon, S. J. Park, J. Heo, and K. Kim, Organometallics, 17, 3161 (1998).

h) H. Hagihara, T. Shiono, and T. Ikeda, Macromolecules, 31, 3184 (1998).

i) Y. Fukui, M. Murata, and K. Soga, Macromol. Rapid Commun., 20, 637 (1999).

j) K. C. Jayaratne and L. R. Sita, J. Am. Chem. Soc., 122, 958 (2000).

k) E. Y. Tshuva, I. Goldberg, and M. Kol, J. Am. Chem. Soc., 122, 10706 (2000).

1) Z. Hou, Y. Zhang, H. Tezuka, P. Xie, O. Tardif, T. Koizumi, H. Yamazaki, and Y. Wakatsuki, J. Am. Chem. Soc., 122, 10533 (2000).

m) T. Matsugi, S. Matsui, S. Kojoh, Y. Takagi, Y. Inoue, T. Fujita, and N. Kashiwa, Macromolecules, 35, 4880 (2002). n) J. C. Jansen, R. Mendichi, M. C. Sacchi, and I. Tritto, Macromol. Chem. Phys., 204, 522 (2003).

o) X. F. Li, K. Dai, W. P. Ye, L. Pan, and Y. S. Li, Organometallics, 23, 1223 (2004).

p) V. Busico, R. Cipullo, N. Friederichs, S. Ronca, and M. Togrou, Macromolecules, 36, 3806 (2003).

q) S. Bambirra, D. van Leusen, A. Meetsma, B. Hessen, and J. H. Teuben, Chem. Commun., 522 (2003).

r) Y. Yoshida, J. Mohri, S. Ishii, M. Mitani, J. Saito, S. Matsui, H. Makio, T. Nakano, H. Tanaka, M. Onda, Y. Yamamoto, A. Mizuno, and T. Fujita, J. Am. Chem. Soc., 126, 12023 (2004).

s) H. Zhang and K. Nomura, J. Am. Chem. Soc., 127, 9364 (2005).

t) Y. Yoshida, S. Matsui, and T. Fujita, J. Organomet. Chem., 690, 4382 (2005).

u) A. E. Cherian, J. M. Rose, E. B. Lobkovsky, and G. W. Coates, J. Am. Chem. Soc., 127, 13770 (2005).

v) X. Li, J. Baldamus, and Z. Hou, Angew. Chem., Int. Ed., 44, 962 (2005).

w) Z. Cai, M. Shigemasa, Y. Nakayama, and T. Shiono, Macromolecules, 39, 6321 (2006).

5. For recent reviews, see: a) G. W. Coates, P. D. Hustad, and S. Reinartz, Angew. Chem., Int. Ed., 41, 2236 (2002).

b) B. Liu, H. Matsuoka, and M. Terano, Macromol. Rapid Commun., 22, 1 (2001).

c) For living olefin polymerization with phenoxy-based catalysts, see: ref. $3 \mathrm{j}$.

6. For a basic patent on FI catalysts, see: T. Fujita, Y. Tohi, M. Mitani, S. Matsui, J. Saito, M. Nitabaru, K. Sugi, H. Makio, and T. Tsutsui, Eur. Patent 0874005, 1998 (filed in April 1997).

7. For reviews: a) S. Matsui and T. Fujita, Catal. Today, 66, 63 (2001).

b) H. Makio, N. Kashiwa, and T. Fujita, Adv. Synth. Catal., 344, 477 (2002).

c) N. Matsukawa, S. Ishii, R. Furuyama, J. Saito, M. Mitani,
H. Makio, H. Tanaka, and T. Fujita, e-Polymers, 2003, no. 021 (http://www.e-Polymers.org).

d) M. Mitani, J. Saito, S. Ishii, Y. Nakayama, H. Makio, N. Matsukawa, S. Matsui, J. Mohri, R. Furuyama, H. Terao, H. Bando, H. Tanaka, and T. Fujita, Chem. Rec., 4, 137 (2004). e) Y. Nakayama, H. Bando, Y. Sonobe, and T. Fujita, Bull. Chem. Soc. Jpn., 77, 617 (2004).

f) K. Michiue, S. Matsui, Y. Yoshida, and T. Fujita, Recent Res. Dev. Chem., 2, 191 (2004).

g) H. Makio and T. Fujita, Bull. Chem. Soc. Jpn., 78, 52 (2005).

h) Y. Nakayama, J. Saito, H. Bando, and T. Fujita, Chem. Eur. J., 12, 7546 (2006).

8. a) S. Matsui, Y. Tohi, M. Mitani, J. Saito, H. Makio, H. Tanaka, M. Nitabaru, T. Nakano, and T. Fujita, Chem. Lett., 28, 1065 (1999).

b) J. Saito, M. Mitani, S. Matsui, N. Kashiwa, and T. Fujita, Macromol. Rapid Commun., 21, 1333 (2000).

c) N. Matsukawa, S. Matsui, M. Mitani, J. Saito, K. Tsuru, N. Kashiwa, and T. Fujita, J. Mol. Catal. A: Chem., 169, 99 (2001).

d) S. Matsui, M. Mitani, J. Saito, Y. Tohi, H. Makio, N. Matsukawa, Y. Takagi, K. Tsuru, M. Nitabaru, T. Nakano, H. Tanaka, N. Kashiwa, and T. Fujita, J. Am. Chem. Soc., 123, 6847 (2001).

e) S. Ishii, J. Saito, M. Mitani, J. Mohri, N. Matsukawa, Y. Tohi, S. Matsui, N. Kashiwa, and T. Fujita, J. Mol. Catal. A: Chem., 179, 11 (2002).

f) S. Ishii, J. Saito, S. Matsuura, Y. Suzuki, R. Furuyama, M. Mitani, T. Nakano, N. Kashiwa, and T. Fujita, Macromol. Rapid Commun., 23, 693 (2002).

g) R. Furuyama, J. Saito, S. Ishii, M. Mitani, S. Matsui, Y. Tohi, H. Makio, N. Matsukawa, H. Tanaka, and T. Fujita, J. Mol. Catal. A: Chem., 200, 31 (2003).

h) Y. Nakayama, H. Bando, Y. Sonobe, H. Kaneko, N. Kashiwa, and T. Fujita, J. Catal., 215, 171 (2003).

9. For a basic patent on living ethylene and propylene polymerization and block copolymer formation with Ti-FI catalysts, see: M. Mitani, Y. Yoshida, J. Mohri, K. Tsuru, S. Ishii, S. Kojoh, T. Matsugi, J. Saito, N. Matsukawa, S. Matsui, T. Nakano, H. Tanaka, N. Kashiwa, and T. Fujita, WO Patent 01/55231 A1, 2001 (filed in January 2000). For a patent on modified Ti-FI catalysts relating to the basic patent, see: G. W. Coates, J. Tian, and P. D. Hustad, US Patent 6562930, 2003 (filed in September 2001).

10. For reviews: a) M. Mitani, T. Nakano, and T. Fujita, Chem. Eur. J., 9, 2396 (2003).

b) R. Furuyama, J. Saito, S. Ishii, H. Makio, M. Mitani, H. Tanaka, and T. Fujita, J. Organomet. Chem., 690, 4398 (2005).

11. a) J. Saito, M. Mitani, J. Mohri, Y. Yoshida, S. Matsui, S. Ishii, S. Kojoh, N. Kashiwa, and T. Fujita, Angew. Chem., Int. Ed., 40, 2918 (2001).

b) J. Saito, M. Mitani, J. Mohri, S. Ishii, Y. Yoshida, T. Matsugi, S. Kojoh, N. Kashiwa, and T. Fujita, Chem. Lett., 30, 576 (2001).

c) J. Saito, M. Mitani, M. Onda, J. Mohri, S. Ishii, Y. Yoshida, T. Nakano, H. Tanaka, T. Matsugi, S. Kojoh, N. Kashiwa, and T. Fujita, Macromol. Rapid Commun., 22, 
1072 (2001).

12. a) J. Tian, P. D. Hustad, and G. W. Coates, J. Am. Chem. Soc., 123, 5134 (2001).

b) M. Fujita and G. W. Coates, Macromolecules, 35, 9640 (2002).

c) J. Tian, P. D. Hustad, and G. W. Coates, J. Am. Chem. Soc., 124, 3614 (2002).

d) M. Lamberti, D. Pappalardo, A. Zambelli, and C. Pellecchia, Macromolecules, 35, 658 (2002).

e) M.-S. Weiser and R. Mülhaupt, Macromol. Symp., 236, 111 (2006).

13. For recent papers on FI catalysts and related complexes: a) M. Mazzeo, M. Strianese, M. Lamberti, I. Santoriello, and C. Pellecchia, Macromolecules, 39, 7812 (2006).

b) G. J. Clarkson, V. C. Gibson, P. K. Y. Goh, M. L. Hammond, P. D. Knight, P. Scott, T. M. Smit, A. J. P. White, and D. J. Williams, Dalton Trans., 5484 (2006).

c) D. J. Arriola, E. M. Carnahan, P. D. Hustad, R. L. Kuhlman, and T. T. Wenzel, Science, 312, 714 (2006).

d) J. Saito, Y. Suzuki, H. Makio, H. Tanaka, M. Onda, and T. Fujita, Macromolecules, 39, 4023 (2006).

e) J. Saito, Y. Tohi, S. Matsui, M. Mitani, and T. Fujita, Macromolecules, 38, 4955 (2005).

f) A. E. Cherian, E. B. Lobkovsky, and G. W. Coates, Macromolecules, 38, 6259 (2005).

g) M. Lamberti, M. Consolmagno, M. Mazzeo, and C. Pellecchia, Macromol. Rapid Commun., 26, 1866 (2005).

h) D. A. Pennington, S. J. Coles, M. B. Hursthouse, M. Bochmann, and S. J. Lancaster, Chem. Commun., 3150 (2005).

i) D. A. Pennington, W. Clegg, S. J. Coles, R. W. Harrington, M. B. Hursthouse, D. L. Hughes, M. E. Light, M. Schormann, M. Bochmann, and S. J. Lancaster, Dalton Trans., 561 (2005).

j) K. P. Bryliakov, E. A. Kravtsov, D. A. Pennington, S. J. Lancaster, M. Bochmann, H. H. Brintzinger, and E. P. Talsi, Organometallics, 24, 5660 (2005).

k) R. K. J. Bott, M. Hammond, P. N. Horton, S. J. Lancaster, M. Bochmann, and P. Scott, Dalton Trans., 3611 (2005).

1) H. Zhu, M. Wang, C. Ma, B. Li, C. Chen, and L. Sun, J. Organomet. Chem., 690, 3929 (2005).

m) C.-H. Qi, S.-B. Zhang, and J.-H. Sun, J. Organomet. Chem., 690, 3946 (2005).

n) M. Van Meurs, G. J. P. Britovsek, V. C. Gibson, and S. A. Cohen, J. Am. Chem. Soc., 127, 9913 (2005).

o) H. Terao, S. Ishii, J. Saito, S. Matsuura, M. Mitani, N. Nagai, H. Tanaka, and T. Fujita, Macromolecules, 39, 8584 (2006).

14. S. Reinartz, A. F. Mason, E. B. Lobkovsky, and G. W. Coates, Organometallics, 22, 2542 (2003).

15. Y. Suzuki, T. Oshiki, H. Tanaka, K. Takai, and T. Fujita, Chem. Lett., 34, 1458 (2005).

16. S. Ishii, R. Furuyama, N. Matsukawa, J. Saito, M. Mitani, H. Tanaka, and T. Fujita, Macromol. Rapid Commun., 24, 452 (2003)

17. Although, normally, fluorinated Zr-FI catalysts do not initiate living ethylene polymerization, a fluorinated $\mathrm{Zr}-\mathrm{FI}$ catalyst 31 with iodines in ligand with MAO activation polymerizes ethylene in a quasi-living fashion (linear relation- ship between $M_{\mathrm{n}}$ and ethylene consumption) and produces ultra-high molecular weight $\mathrm{PE}$ with a narrow molecular weight distribution $\left(M_{\mathrm{n}} 2300000, M_{\mathrm{w}} / M_{\mathrm{n}} 1.12\right)$, see ref. 19e. This fact may open up new possibilities for fluorinated Zr-FI catalysts engaged in living olefin polymerization.

18. M. Mitani, J. Mohri, Y. Yoshida, J. Saito, S. Ishii, K. Tsuru, S. Matsui, R. Furuyama, T. Nakano, H. Tanaka, S. Kojoh, T. Matsugi, N. Kashiwa, and T. Fujita, J. Am. Chem. Soc., 124, 3327 (2002).

19. a) M.-S. Weiser, M. Wesolek, and R. Mülhaupt, J. Organomet. Chem., 691, 2945 (2006).

b) M.-S. Weiser, Y. Thomann, L.-C. Heinz, H. Pasch, and R. Mülhaupt, Polymer, 47, 4505 (2006).

c) M.-S. Weiser and R. Mülhaupt, Macromol. Rapid Commun., 27, 1009 (2006).

d) L.-C. Heinz, M.-S. Weiser, T. Macko, R. Mülhaupt, and H. Pasch, Int. J. Polym. Anal. Charact., 11, 47 (2006).

e) M.-S. Weiser, $\mathrm{PhD}$ thesis, Albert-Ludwigs-University Freiburg (Germany), 2006.

20. R. Furuyama, M. Mitani, J. Mohri, R. Mori, H. Tanaka, and T. Fujita, Macromolecules, 38, 1546 (2005).

21. Regarding the effect of the incorporation of $\mathrm{F}(\mathrm{s})$ and $\mathrm{CF}_{3}(\mathrm{~s})$ to Ti-FI catalysts on catalytic performance, Ishii and Fujita have revealed that Ti-FI catalysts having plural $\mathrm{F}(\mathrm{s})$ or $\mathrm{CF}_{3}$ (s) in the phenyl group on the imine-N, in particular in the meta-positions, display extremely enhanced catalytic activity for ethylene polymerization, see ref. 8e; this effect has been confirmed for propylene polymerization using similar Ti-FI catalysts by Mason, Cherian and Coates, see ref. $13 \mathrm{f}$ and 25.

22. a) M. Mitani, R. Furuyama, J. Mohri, J. Saito, S. Ishii, H. Terao, N. Kashiwa, and T. Fujita, J. Am. Chem. Soc., 124, 7888 (2002).

b) M. Mitani, R. Furuyama, J. Mohri, J. Saito, S. Ishii, H. Terao, T. Nakano, H. Tanaka, and T. Fujita, J. Am. Chem. Soc., 125, 4293 (2003).

23. G. Milano, L. Cavallo, and G. Guerra, J. Am. Chem. Soc., 124, 13368 (2002).

24. a) X. Bei, D. C. Swenson, and R. F. Jordan, Organometallics, 16, 3282 (1997).

b) Y. Tohi, S. Matsui, H. Makio, M. Onda, and T. Fujita, Macromolecules, 36, 523 (2003).

c) Y. Tohi, T. Nakano, H. Makio, S. Matsui, T. Fujita, and T. Yamaguchi, Macromol. Chem. Phys., 205, 1179 (2004).

25. A. F. Mason, J. Tian, P. D. Hustad, E. B. Lobkovsky, and G. W. Coates, Isr. J. Chem., 42, 301 (2002).

26. J. Tian and G. W. Coates, Angew. Chem., Int. Ed., 39, 3626 (2000).

27. A. F. Mason and G. W. Coates, J. Am. Chem. Soc., 126, 10798 (2004).

28. Y. Nakayama, J. Saito, H. Bando, and T. Fujita, Macromol. Chem. Phys., 206, 1847 (2005).

29. a) D. Veghini, L. M. Henling, T. J. Burkhardt, and J. E. Bercaw, J. Am. Chem. Soc., 121, 564 (1999).

b) V. Busico, R. Cipullo, F. Cutillo, G. Talarico, and A. Razavi, Macromol. Chem. Phys., 204, 1269 (2003).

c) L. J. Irwin and S. A. Miller, J. Am. Chem. Soc., 127, 9972 (2005).

30. C. De Rosa, T. Circelli, F. Aurimma, R. T. Mathers, and 
G. W. Coates, Macromolecules, 37, 9034 (2004).

31. a) J. Saito, M. Onda, S. Matsui, M. Mitani, R. Furuyama, H. Tanaka, and T. Fujita, Macromol. Rapid Commun., 23, 1118 (2002).

b) A. V. Prasad, H. Makio, J. Saito, M. Onda, and T. Fujita, Chem. Lett., 33, 250 (2004).

32. A. F. Mason and G. W. Coates, J. Am. Chem. Soc., 126, 16326 (2004).

33. S. Ishii and T. Fujita, unpublished results.

34. S. Kojoh, T. Matsugi, J. Saito, M. Mitani, T. Fujita, and N. Kashiwa, Chem. Lett., 30, 822 (2001).

35. P. D. Hustad and G. W. Coates, J. Am. Chem. Soc., 124, 11578 (2002).

36. R. T. Mathers and G. W. Coates, Chem. Commun., 422 (2004).

37. H. Makio and T. Fujita, JP 2005-97588 (2005).

38. G. Talarico, V. Busico, and L. Cavallo, Organometallics, 23, 5989 (2004).

39. a) S. C. F. Kui, N. Zhu, and M. C. W. Chan, Angew. Chem., Int. Ed., 42, 1628 (2003).

b) M. C. W. Chan, S. C. F. Kui, J. M. Cole, G. J. McIntyre, S. Matsui, N. Zhu, and K.-H. Tam, Chem. Eur. J., 12, 2607
(2006).

40. Y. Suzuki, H. Tanaka, T. Oshiki, K. Takai, and T. Fujita, Chem. Asian J., 1, 878 (2006).

41. H. Makio and T. Fujita, Macromol. Symp., 213, 221 (2004).

42. H. Makio, T. Oshiki, K. Takai, and T. Fujita, Chem. Lett., 34, 1382 (2005).

43. M. Mitani, J. Mohri, R. Furuyama, S. Ishii, and T. Fujita, Chem. Lett., 32, 238 (2003).

44. J. Yoon, R. T. Mathers, G. W. Coates, and E. L. Thomas, Macromolecules, 39, 1913 (2006).

45. K. Michiue, M. Onda, M. Mitani, and T. Fujita, "Studies in Surface Science and Catalysis (Progress in Olefin Polymerization Catalysts and Polyolefin Materials)," Elsevier Scinece B. V., in press.

46. S. S. Ono, T. Matsugi, N. Matsukawa, S. Kojoh, T. Fujita, N. Kashiwa, and S. Yamamoto, Chem. Lett., 32, 1182 (2003).

47. J. Ruokolaine, R. Mezzenga, G. H. Fredrickson, E. J. Kramer, P. D. Hustad, and G. W. Coates, Macromolecules, 38, 851 (2005).

48. A. Radulescu, R. T. Mathers, G. W. Coates, D. Richter, and L. J. Fetters, Macromolecules, 37, 6962 (2004).

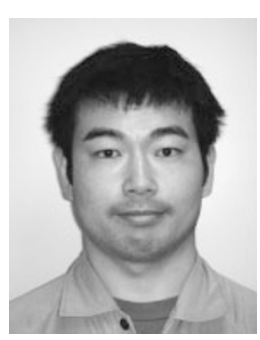

Atsushi Sakuma was born in June 1978 in Hokkaido, Japan. He received his B.S. and M.S. degrees in organometallic chemistry from Tohoku University working with Professors Hiroshi Ogino and Hiromi Tobita. He joined Mitsui Chemicals, Inc., in 2003 as a researcher. His research interests include organometallic chemistry and olefin polymerization catalysts.

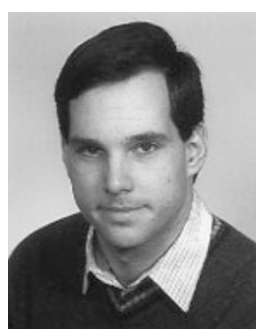

Marc-Stephan Weiser was born in April 1977 in Neu-Ulm, Germany. He received his Diploma degree for Chemistry at the University of Bayreuth, Germany, working with Professor H. G. Alt. He obtained his Ph.D. degree at the Freiburg Materials Research Center of the Albert-Ludwigs-University of Freiburg i. Br., Germany, in 2006 under the direction of Professor R. Mülhaupt. He joined Mitsui Chemicals, Inc., in May 2006 in a post-doctoral research position. His research interests include catalysis and polyolefin chemistry.

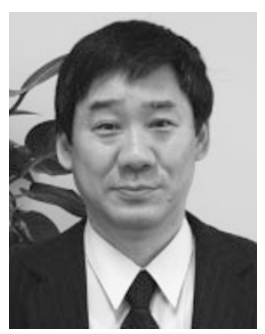

Terunori Fujita was born in November 1957 in Ehime, Japan. He received his B.S. degree in 1980 and his M.S. degree in 1982, both in chemistry from Hokkaido University, working with Professors Takeshi Matsumoto and Haruhisa Shirahama. He obtained his Ph.D. degree in 1988 in organic chemistry from the Louis Pasteur University at Strasbourg, France, under the guidance of Professor Jean-Marie Lehn. He joined Mitsui Petrochemical Industries, Ltd. (now Mitsui Chemicals, Inc.) in 1982, where he is now the general manager of the catalysis science laboratory, and at the same time, one of eleven Mitsui research fellows. His research interests are in homogeneous and heterogeneous catalysis, leading to the synthesis of valuable organic materials with high efficiency, particularly the development of high performance olefin polymerization catalysts and their applications to new value-added materials. He has about 400 patents and 110 publications including original research papers, reviews and book contributions. He has received a number of awards, which include the Chemical Society of Japan Award for Creative Work (2003), and the Award of the Society of Polymer Science, Japan (2005). 